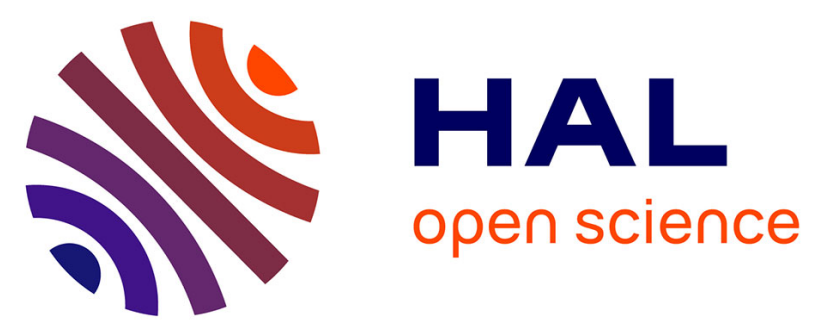

\title{
Evaluation of retrieved aerosol extinction profiles using as reference the aerosol optical depth differences between various heights
}

\author{
M. Herreras, R. Román, A. Cazorla, C. Toledano, H. Lyamani, B. Torres, \\ V.E. Cachorro, F.J. Olmo, L. Alados-Arboledas, A.M. de Frutos
}

\section{To cite this version:}

M. Herreras, R. Román, A. Cazorla, C. Toledano, H. Lyamani, et al.. Evaluation of retrieved aerosol extinction profiles using as reference the aerosol optical depth differences between various heights. Atmospheric Research, 2019, 230, pp.104625 -. 10.1016/j.atmosres.2019.104625 . hal-03487290

\author{
HAL Id: hal-03487290 \\ https://hal.science/hal-03487290
}

Submitted on 20 Dec 2021

HAL is a multi-disciplinary open access archive for the deposit and dissemination of scientific research documents, whether they are published or not. The documents may come from teaching and research institutions in France or abroad, or from public or private research centers.
L'archive ouverte pluridisciplinaire HAL, est destinée au dépôt et à la diffusion de documents scientifiques de niveau recherche, publiés ou non, émanant des établissements d'enseignement et de recherche français ou étrangers, des laboratoires publics ou privés.

\section{(ㅇ)(1) $\$$}

Distributed under a Creative Commons Attribution - NonCommerciall 4.0 International 


\title{
EVALUATION OF RETRIEVED AEROSOL EXTINCTION PROFILES USING AS REFERENCE THE AEROSOL OPTICAL DEPTH DIFFERENCES BETWEEN VARIOUS HEIGHTS
}

\author{
M. Herreras ${ }^{1,2,3}$, R. Román ${ }^{1}$, A. Cazorla ${ }^{4,5}$, C. Toledano ${ }^{1}$, H. Lyamani ${ }^{4,5}$, B. Torres ${ }^{3}$, V.E. Cachorro ${ }^{1}$, F.J. \\ $\mathrm{Olmo}^{4,5}$, L. Alados-Arboledas ${ }^{4,5}$, A.M. de Frutos ${ }^{1}$ \\ ${ }^{1}$ Atmospheric Optics Group (GOA), University of Valladolid, Spain \\ ${ }^{2}$ GRASP-SAS, Remote sensing developments, Université des Sciences et Technologies de Lille, Villeneuve \\ d'Ascq, France \\ ${ }^{3}$ Laboratoire d'Optique Atmosphérique, University of Lille 1, France \\ ${ }^{4}$ Department of Applied Physics, University of Granada, Granada, Spain \\ ${ }^{5}$ Andalusian Institute for Earth System Research (IISTA-CEAMA), Granada, Spain
}

Keywords: Ceilometer, Aerosol Extinction, GRASP, AERONET, Photometer, Aerosol Profiling

\section{Abstract}

Aerosol extinction vertical profiles at Granada (Spain) are calculated with the GRASP (Generalized Retrieval of Aerosol and Surface Properties) code using as input Aerosol Optical Depth (AOD) and sky radiance measurements from AERONET (AEerosol RObotic NETwork) and ceilometer RCS (Range Corrected Signal) profiles, both corresponding to the Granada (Spain) station. This methodology is so called GRASP pac $_{\text {due }}$ to the combination of sun/sky photometer and ceilometer on GRASP. In order to evaluate the accuracy of these retrieved extinction profiles at Granada, two more nearby AERONET stations, located at different altitudes, are used. The AOD difference of the three choosen AERONET sun/sky photometers have been used to calculate the Integrated Aerosol Extinction (IAE) at different height layers. These three AERONET sun/sky photometers are used as a reference and compared against the integrated extinction at the same layers from the extinction profiles retrieved by GRASP pac $_{\text {. The differences between AERONET and GRASP }}$ pac retrieved IAE values indicate that GRASP $_{p a c}$ aerosol extinction profiles are at least within the uncertainty of the sun/sky

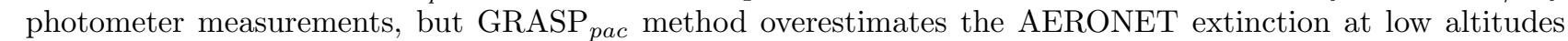
and underestimates it at high levels. The most accurate and precise retrieved extinction correspond to the intermediate layer with a mean bias error (MBE \pm standard deviation) of $0.00 \pm 0.01(0 \pm 59 \%)$ for $1020 \mathrm{~nm}$, and the worst integrated extinction results were obtained for the upper layers with a MBE of $-0.01 \pm 0.02$ (28 $\pm 36 \%$ ) for $1020 \mathrm{~nm}$. In general these MBE values increases for shorter wavelengths. In order to obtain a complete characterization of this bias, the dependence of the obtained differences on the aerosol size and the solar zenith angle, among others, are analysed in detail. Finally, the behaviour of vertically-resolved aerosol extinction at Granada is evaluated using averages of the retrieved profiles from November of 2012 to December of 2017. The highest IAE values are found in Summer with mean values of 0.09 for the lower layers and 0.07 for the upper ones, both at $440 \mathrm{~nm}$ wavelength.

\section{Introduction}

The influence of atmospheric aerosols, particles suspended in the atmosphere [1], on the Earth radiative budget and some atmospheric processes plays a key role in the global warming and climate change fields. Aerosols contribute mainly in two processes [2]: "aerosol-radiation interaction" mainly based on the direct scattering and absorption of the incoming solar and outgoing infrared radiation; and "aerosol-cloud interaction" by acting mainly as cloud condensation and ice nuclei, influencing cloud properties, as droplets size and cloud lifetime, and precipitation processes. Despite the significant impact of aerosols in climate, the IPCC (Intergovernmental Panel on Climate Change) [2] points out that aerosols are still one of the most unknown parts of the climate system, showing one of the largest amounts of uncertainty within the global radiative forcing. The main reasons behind this uncertainty are their high temporal and spatial variability, and their vast source origin.

Columnar aerosol properties are commonly retrieved using sun/sky photometers, as in AERONET (Aerosol Robotic NETwork) [3][4]. This network provides aerosol information from two kinds of multi-wavelength measurements: direct Sun irradiance, which is used to derive the AOD at several wavelengths, and angular distribution of diffuse sky radiation. Despite the long-term reliability of AERONET measurements, only column integrated aerosol properties can be retrieved from them, e.g. [5], but aerosol vertical profiles are also important in the fields of climate change, air quality and aviation, among others.

LiDAR (Light Detection And Ranging) systems are frequently used for profiling aerosol vertical properties. This type of instruments are formed by an active pulsed laser emitter and an optical detector. LiDAR technique is based on the measurement of the backscattering produced by the atmosphere of the emitted laser pulse [6]. The vertical resolution is obtained through the measurement of the "flight time" of the emitted laser pulses. The high vertical and time resolution are its main advantages; but the elevated instrument cost and complex 
composition, as well as its short time lapses of measurement are its main drawbacks. At the moment, there is no standard LiDAR instrument, however, EARLINET (European Aerosol Research LiDAR NETwork)[7] guarantees the standardization and homogenization of the data.

GRASP (Generalized Retrieval of Aerosol and Surface Properties) code [8] is an open algorithm which following GARRLiC/GRASP strategy [9], where multi-wavelength LiDAR and sun/sky photometer measurements are combined, enables the retrieval of optical and micro-physical aerosol properties. Due to LiDAR technical characteristics, two aerosol modes (coarse and fine) are available along the column. Thus, an independent characterization for both modes of vertical extinction profiles, SSA (Single Scattering Albedo) or complex refractive index, between others, can be obtained as in [10].

Despite the advantages of multi-wavelength LiDAR instruments, its elevated cost and operative difficulties are the responsible of its scarce geographical distribution. Ceilometers are instruments based on LiDAR technique measuring at just one wavelength and with less energy pulse, thus, they provide backscattering profiles with lower singal-to-noise ratio than common multiwavelength LiDAR instruments. But ceilometers are cheaper and they can work continuously unattended [11]. These advantages favoured a high ceilometer geographical density, which allows a well three-dimensional aerosol monitoring. In order to homogenize ceilometer data, there are also ceilometer networks, such as the Iberian CEilometer NETwork (ICENET) [12] or E-PROFILE (http://www.eumetnet.eu/e-profile) among others. The technical limitations of these instruments lie in their restriction to only one wavelength, and the lower laser power, which makes it difficult to obtain signal information at high altitude and provides a low signal-to-noise ratio.

Recently, a new method, called GRASP ${ }_{p a c}$ has been proposed by [13] to obtain profiles of extensive aerosol properties combining ceilometer and sun/sky photometer measurements on GRASP code. In comparison with GARRLiC procedure where multiwavelength LiDAR signal and multispectral sun/sky photometer measurements are used as input into the algorithm, which enables the retrieval of aerosol properties for both fine and coarse modes, the use of single-wavelength ceilometer signal in combination with sun/sky photometer measurements does not allow to discern aerosol modes with vertical resolution. This fact implies the assumption of the same intensive aerosol properties for all atmospheric column. The main information provided by the ceilometer signal to the inversion is the vertical distribution of aerosol along the column, which cannot be appreciated if only sun/sky photometer measurements were used. In [13] a high correlation were found between the GRASP ${ }_{p a c}$ retrieved aerosol volume concentration and airborne and in-situ measurements. However, other aerosol properties retrieved by this new method, such us aerosol extinction, have not been compared against real measurements yet.

In this framework, and in order to evaluate the mentioned method, the main objective of this work is to quantify the accuracy and uncertainty of the aerosol extinction product provided by GRASP ${ }_{p a c}$. Despite the positive results obtained by the mentioned method, there are still some degree of unexplained uncertainty. Once the accuracy of the method is characterized, GRASP ${ }_{p a c}$ will be used to characterised the seasonal averages of the aerosol extinction vertical profiles at Granada.

Different sun/sky photometers located at different heights have been selected to characterized independently different layers of the inverted profile. The dependence of the differences, between AERONET and GRASP ${ }_{\text {pac }}$ methodologies, on AOD (Aerosol Optical Depth), IAE (Integrated Aerosol Extinction), aerosol size and solar zenith angle are analysed in detail. The reasons behind the election of these magnitudes are the analysis of the influence in the retrieved profiles of the aerosol amount, type and vertical distribution, and the measurement geometry.

The structure of this paper is the following: section 2 presents the instrumentation and locations used in this study, while section 3 shows the followed methodology, in section 4 the results of the analysis are shown including all the studied bias. In section 5 the aerosol vertical extinction profiles are presented, and finally, section 6 summarizes the main conclusions.

\section{Location, Instrumentation and Data description}

\subsection{Experimental sites and equipments}

This work is mainly related with a ground-based UGR station (GR; 37 $09^{\prime} 50^{\prime \prime} \mathrm{N} ; 3^{\circ} 36^{\prime} 18^{\prime \prime} \mathrm{W} ; 680 \mathrm{~m}$ a.s.l.) at Granada (Spain), managed by the Atmospheric Physic Group (GFAT) of Granada University. The station, which belongs to the Andalusian Institute for Earth System Research, IISTA/CEAMA of the University of Granada is part of the Andalusian Global ObseRvatory of the Atmosphere (AGORA).

Granada is a medium-size city with a total population of 530000 inhabitants considering all the metropolitan area. The city is located in the South-East of the Iberian Peninsula, in a natural basin surrounded by mountains. Granada shows a Mediterranean continental climate being its local aerosol sources the heavy traffic along all the year in addition to the heating systems based on fuel oil combustion in winter [14]. Furthermore, due to its proximity to the African continent, Granada is usually affected by Saharan dust intrusions, specially in summer 
$[15]$

The Granada station is equipped with, among other instruments, a sun/sky photometer (CE318; Cimel Electronique) which since 2004 which belongs to AERONET. In addition to Granada station, two AERONET stations both equipped with a CE318 photometer, managed also by GFAT, are included in this work due to their high altitude and their proximity to Granada station (see Fig. 1). These stations are Cerro_Poyos (CP; $37^{\circ} 06^{\prime} 28^{\prime \prime} \mathrm{N} ; 3^{\circ} 29^{\prime} 13^{\prime \prime} \mathrm{W}$; $1830 \mathrm{~m}$ a.s.l.), and Albergue_UGR (AU; 37 $05^{\circ} 45^{\prime \prime} \mathrm{N} ; 3^{\circ} 23^{\prime} 13^{\prime \prime} \mathrm{W} ; 2501 \mathrm{~m}$ a.s.l.); both also belong to AGORA and are located at Sierra-Nevada Mountain range as can be observed in Fig. 1. Sun/sky photometer data at $\mathrm{CP}$ are available since 2011, while for AU the first measurements were recorded in spring 2016. The sun/sky photometers at AU and CP are usually operative only in spring and summer due to snowfall in autumn and winter.

The three sun/sky photometers (GR, CP and AU) included in this study belong to ACTRIS/AERONETEurope, the European branch of AERONET. Thus, the three instruments are routinely calibrated following the same protocol and the data are quality-controlled. The sun/sky photometer measures direct solar irradiance (at least at 340, 380, 440, 500, 675, 870 and $1020 \mathrm{~nm}$ ) allowing the computing of AOD, and sky radiance measurements (Almucantar geometry) at 440,675, 870 and $1020 \mathrm{~nm}$. The AERONET AOD uncertainty ranges from \pm 0.01 in the infrared-visible to \pm 0.02 in the ultraviolet channels [3].

AOD and sky radiances both at 440,675, 870 and $1020 \mathrm{~nm}$ obtained by sun/sky photometer at Granada have been obtained from AERONET (version 2 level 1.5). AOD at the same wavelengths have been also obtained from AERONET (version 2 level 1.5) for Cerro_Poyos and Albergue_UGR. Due to technical and meteorological issues not all the stations present the same range of temporal coverage:

- GR: From 01/11/2012 to $12 / 12 / 2017$.

- CP: From 02/11/2012 to 11/10/2017.

- AU: From 07/06/2016 to 07/12/2017.

The Granada station is also equipped with a ceilometer CHM15k-Nimbus (Lufft manufacturer) since 2012, which belongs to ICENET and E-PROFILE. This instrument emits at $1064 \mathrm{~nm}$ with a pulsed Nd:YAG laser. The energy per pulse is $8.4 \mu J$ with a repetition frequency in the range of $5-7 \mathrm{kHz}$, with a vertical resolution of $15 \mathrm{~m}$. The vertical measurement range of the ceilometer covers from $15 \mathrm{~m}$ a.g.l. to $15 \mathrm{~km}$ a.g.l. It operates with a temporal resolution of $15 \mathrm{~s}$. For more technical information about CHM15k-Nimbus and its retrieved products see [16]. For this study the Range Corrected Signal (RCS) at $1064 \mathrm{~nm}$ and the detected cloud base height data (in order to discard profiles with clouds) has been selected from all the products available of CHM15kNimbus. Regarding the limitations of the ceilometer profile, the full overlap region is situated around $1220 \mathrm{~m}$ a.g.l. The overlap correction applied by the manufacturer provides a suitable signal for our purpose from 250 meters a.g.l. Where the physical overlap reached is $20 \%$. A lower overlap height would be desirable in order to characterized better the Planetary Boundary Layer (PBL), as for example the Vaisala ceilometer counts with a overlap corrected signal from 80 meters a.g.l [17]. However, an advantage of CHM15k-Nimbus instrument is that it does not need a correction of water vapor in the atmosphere, which avoids an additional source of uncertainty.

\section{$2.2 \quad$ GRASP $_{p a c}$}

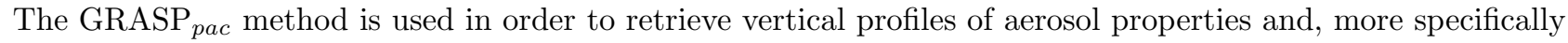
for this study, vertical aerosol extinction profiles.

The input data on GRASP pac $_{\text {are }}$ the AOD and sky radiance (almucantar sequence) both at $440,675,870$ and $1020 \mathrm{~nm}$ from AERONET GR photometer, and vertical ceilometer RCS profile averaged at 60 vertical log-spaced points in an averaged temporal window of \pm 15 minutes around the almucantar measurement. The input data are previously cloud-screened, and some quality control criteria, explained in [13], are applied to ensure that they are suitable enough to obtain quality aerosol retrievals.

The minimum height of the RCS ceilometer data used as input is situated at $250 \mathrm{~m}$ a.g.l. in order to deal with some overlap problems; the retrieval strategy assumes that below this altitude the aerosol extinction is constant. The maximum height of the profiles is situated at $7000 \mathrm{~m}$ a.g.l. However, GRASP pac $_{\text {makes }}$ an iterative process where this upper limit is reduced. This is made to assure that all RCS values used as input of the method are positive, negative RCS values has no physical meaning at all. Despite the different maximum height of some profiles, there is no evidence of a clear influence in the final inversion result. The fully detailed inversion strategy can be found in [13].

Originally starting from the AERONET and ceilometer data described above, 7387 aerosol extinction profiles

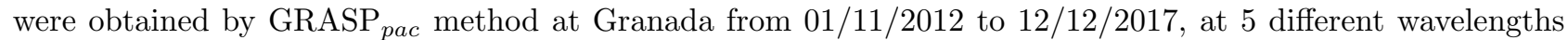
(440, 675, 870, 1020 and $1064 \mathrm{~nm}$ ), corresponding for each almucantar sequence available from sun/sky photometer. 


\section{Methodology}

In order to make an evaluation of the aerosol extinction profiles retrieved by GRASP pac $_{\text {strategy, the two }}$ additional and independent AERONET stations (at different altitudes) closest to Granada, have been selected to perform a comparison between the IAE obtained from both methodologies. The initial assumption of this study is based in supposing that the measurements from the three AERONET stations and the GRASP pac profiles are referred to the same aerosol volume, due to the reasonable short horizontal distance $(\sim 20 \mathrm{~km})$ between the stations.

Five different layers has been choosen to this end:

- CP-TOA (Top Of the Atmosphere) and AU-TOA which are used to analyse the highest part of the profile.

- GR-CP and GR-AU which are used to analyse the lower part of the profile.

- CP-AU which is used to analyse the intermediate part of the profile.

For the sake of clarity in this work the Integrated Aerosol Extinction (IAE) has been selecteed instead of AOD since it is generally used to refer the integration of aerosol extinction from the surface to the TOA.

To obtain the AERONET IAE in the intermediate layers, the difference between the AOD at the stations in the limits of the layer has been calculated. For example, IAE in the layer CP-AU is obtained as the AOD at CP minus AOD at AU. Thus, an independent characterisation of the different parts of the profile can be done. Note that the IAE referred to the layers with the TOA as the upper limit is equal to the usual AOD.

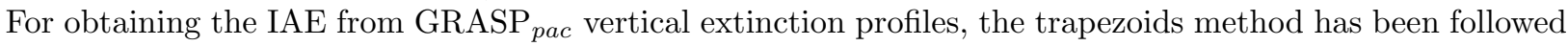
to integrate the profiles between the five selected layers corresponding to the three AERONET stations:

$$
\mathrm{IAE}=\int_{z_{0}}^{z_{1}} \alpha(\lambda, z) d z
$$

Where $\alpha$ corresponds to the aerosol extinction, $z_{0}$ and $z_{1}$ correspond to the initial and final height of the AERONET stations considered (or the TOA) respectively.

Due to the different nature of AERONET and GRASP products, some assumptions have to be done in the calculations of the IAE to make both values comparable:

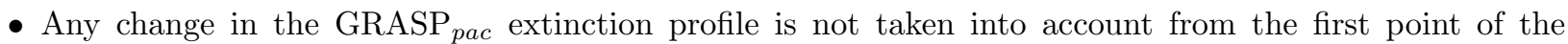
profile to the ground. This assumption is necessary because measurements can not be obtained with the ceilometer under a minimum height where there is enough overlap between the laser and the receptor field of view. Thus, GRASP ${ }_{p a c}$ completes the lower part of the profile with the RCS value of the first height proper for the inversion, henceforth "overlap reference level" ( $\sim 250 \mathrm{~m}$ a.g.l.), from this height to the ground. This assumption will be referred as Assumed Constant Lower (ACL) layer.

- On the other hand, some integrations are made to the top of the atmosphere (TOA assumed as 40 $\mathrm{km}$ ). Thus, in these cases the profiles have been filled following the GARRLiC/GRASP procedure [9], by adding a region of linearly decreasing aerosol concentration (correspondingly extinction) from the

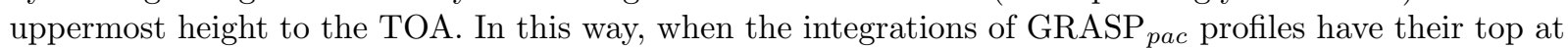
TOA, the AOD values obtained by GRASP are directly comparable with the AERONET ones.

Both assumptions will be discussed in detail later. Earlier, [18] employed a similar methodology to compare satellite AOD measurements at different altitudes with integrated extinction of a Micro Pulsed LiDAR (MPL). Similar assumptions were made about the horizontal atmospheric homogeneity in [18]. In our case no interpolation of the AOD value has to be made due to the punctual character of the sun/sky photometer in comparison with the considerable large grid points of the satellite AOD measurements.

In order to select adequate data to make comparisons the following conditions have been imposed to the IAE series of AERONET and GRASP pac $_{\text {: }}$

- AERONET IAE data which are not within $\pm 5 \mathrm{~min}$ are discarded. The spatial separation of the three AERONET stations is being assumed as zero, thus, a short temporal difference between the measurements is required in order to minimize the errors coming from the difference in the aerosol content of the atmospheric volume measured by each instrument.

- IAE negative values are discarded. In this analysis not only errors from GRASP pac $_{\text {itself }}$ are going to be reflected in the final result, but also all the instantaneous, or systematic, measurement errors are included. The IAE obtained from AERONET AOD values is always calculated as the difference between the AOD of the lower instrument minus the upper one. Thus, if a negative IAE value appears it only can be explained by the sun/sky photometer uncertainties, or by a real difference between the measured atmosphere in each 
station. In any case both situations are undesirable for the objectives of this study. The number of valid and discarded data according to these criteria can be found in table 1. It is notorious the high number of negative IAE values obtained in CP-AU layer, but it has to be taken into account the small depth of this layer. Thus, as it can be seen also in table 1, the majority of data of this layer is within the limit of the AERONET photometer uncertainty.

- A valid IAE value is assumed only when IAE data at all wavelengths are available and they satisfy the previous quality criteria. As in the previous case this filter is established to avoid all errors originated from instrument malfunctions.

The AERONET data is taken as reference for this study due to the high quality and their wide use within the scientific community, and the the high number of studies supporting its methodology (e.g. [4][19] [20]). This methodology has been developed in order to make comparable the two independent procedures to obtain IAE at different layers over the city of Granada. A 3+2 polarized multiwavelength Raman LiDAR is operating at the Granada station as part of ACTRIS/EARLINET, then an interesting comparison between GRASP pac $_{\text {and }}$ the Raman LiDAR extinction profiles could have been made. However, the inversion needed for the retrieval of vertical extinction profiles with this LiDAR is not free of assumptions either. Furthermore, some of these

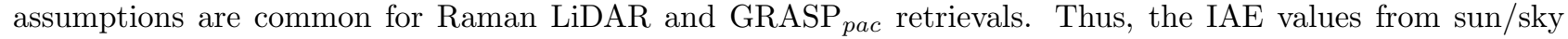
photometers have been chosen as reference instead of LiDAR extinction data since these LiDAR mesurements are based on the same principle than the ceilometer, while sun/sky photometer measurements are independent.

\section{Results}

\subsection{Overall Comparison}

A first general analysis has been done in order to study the agreement between GRASP pac $_{\text {and AERONET }}$ values for the full data set. Figure 2 shows the IAE calculated from both sources (AERONET and GRASP pac $_{\text {) }}$ for the different layers, while the fitting equation, the number of data included in each regression analysis and the determination coefficient are included in table 2. In general a high correlation was found among IAE

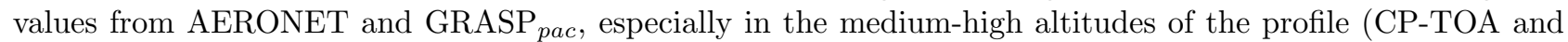
AU-TOA) with values of $r^{2}$ around 0.91 and higher. However, in the lower part the correlation between both IAEs is lower, showing the lowest correlation in the GR-CP and CP-AU layers with values of $r^{2}$ around 0.55. There is a reduction of the dispersion as the wavelength increases (here only 440 and 1020 nm wavelengths are

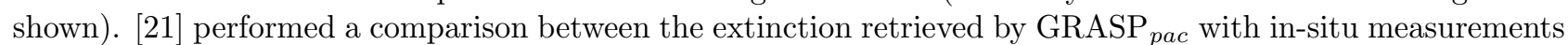
in a station situated 760 meters higher than the ceilometer finding a determination coefficient of 0.73 , which is within the range of the $r^{2}$ obtained here.

An statistical analysis about the differences between the IAE from AERONET and the ones from GRASP pac

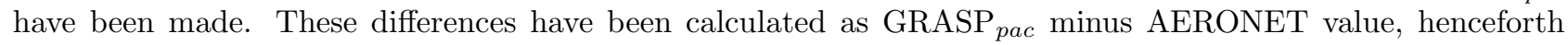
defined as $\triangle \mathrm{IAE}$. The main statisical indices used in this work have been the mean of $\triangle \mathrm{IAE}$ (MBE: Mean Bias Error) and the standard deviation of $\triangle \mathrm{IAE}$ (STD); the three statisicals are shown in table 3 for the different layers and wavelengths. MBE is negative in all the higher layers and wavelengths (GRASP pac $_{\text {underestimates }}$

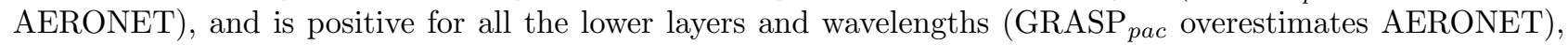
while MBE is very close to zero in the intermediate layers.

In order to have a clearer view of the bias in the upper and lower part of the profile, an histogram of the relative frequency of $\triangle \mathrm{IAE}$ is shown in figure 3 . For the sake of clarity only $\triangle \mathrm{IAE}$ corresponding to 440 and 1020 $\mathrm{nm}$ are shown. According to figure 3, it can be seen how some distributions present a marked skewness showing values deviated to the negative region in CP-TOA and AU-TOA layers, and positively deviated for GR-CP and GR-AU layers. Moreover, the standard deviation of the distributions increases for the lower wavelength. The behavior of the other two wavelengths, not shown here, is in agreement with the tendency observed for the 440 and $1020 \mathrm{~nm}$ ones, MBE and STD decrease with the wavelength.

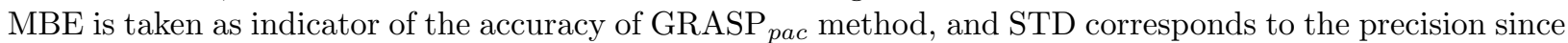
IAE form AERONET has been assumed as the reference. The most accurate IAE values correspond to 1020 $\mathrm{nm}$, where the MBE is closest to zero for all layers; while, the least accuratcy appears for $440 \mathrm{~nm}$ independently of the considered layer. The same pattern is observed for the precision as table 3 points out. This result can be mainly explained by two reasons: the higher AOD values reached at lower wavelengths, and the fact that vertical aerosol information in $\operatorname{GRASP}_{p a c}$ is obtained by ceilometer signal at $1064 \mathrm{~nm}$, which could differ from the real profile for shorter wavelengths. Thus, the lower wavelengths produce higher IAE values in both data sets, despite these measurements keep the same relative precision, the absolute error among them will be higher. The most accurate and precise values appear for the CP-AU layer with a precision of 0.013(55\%) and an accuracy of $0.001(6 \%)$, both averaged for the four wavelengths. On the other hand, the least accurate layer and the one with the worse precision is AU-TOA with a MBE of $-0.031(37 \%)$ and a STD of $0.029(39 \%)$ at 440 
nm. Nevertheless, accuracy and precision have very similar values between both lower layers, and both upper ones, for all available wavelengths.

At the sight of the difference in the number of points which are within the AERONET uncertainty between the different layers (last column of table 1), the assumption of the no-varying extinction below $250 \mathrm{~m}$ a.g.l., the ACL layer, could play a significant role over the rest of the uncertainties. Furthermore, the mean IAE between 250 meters a.g.l. and the ground for all Granada measurements is $0.028,0.018,0.014,0.013$ corresponding to 440, 675, 870 and $1020 \mathrm{~nm}$, respectively; all these IAE values are higher than the MBE of GR-CP and GR-AU showed in table 3. Thus, the extinction presented in this layer is enough to consider ACL assumption as a possible responsible for the observed bias. This ACL assumption has been proved as useful and accurate in several LiDAR studies in which not a special bias of this procedure has been reported. As for example in [22], the same procedure is used in order to compare AOD from LiDAR and sun/sky photometer. Frequently, the aerosol vertical concentration in the lower layers is assumed to increase constantly when the height decreases to the ground, due to the gravity force dragging the aerosols to the ground, and to the fact that the aerosol sources are located in the ground (or very close to it). Thus, an assumption based on no vertical aerosol variation (correspondingly extinction variation) between $250 \mathrm{~m}$ (or higher) to the ground is expected to produce a negative bias of the real aerosol load.

However, what is observed here is the opposite behaviour. The IAE in the lower layers calculated with the GRASP $_{\text {pac }}$ ceilometer profile, which are affected by the ACL layer assumption is higher than the AERONET IAE, which is taken as the reference. Note that GRASP code is a Multiterm-Least-Square fit, which tries to adjust the value of the aerosol extinction profile to the AOD measured in Granada by the AERONET sun/sky photometer. In this way, if IAE in the lower part of the profile is overestimated by the a priori imposed structure of the vertical profile, the extinction corresponding to the higher layers will be underestimated, which explains the negative bias in the higher parts of the profile. This compensation of the overestimation is distributed along all the points of the column. Thus, the results showed in the last column of table 3 are coherent with this GRASP $_{\text {pac }}$ compensation.

Our hypothesis is based in supposing that the highest aerosol concentration in the lower part of the profile is not usually on the ground level, if not in an intermediate height inside the PBL, and it decreases from this point to the ground. This hypothesis will explain the overestimation of the lower layers, because the overlap reference level taken to complete the ceilometer extinction profile to the ground is close to this concentration maximum. Thus, this added extinction is higher than the real one. The ACL assumption could be really representative of the real atmospheric structure, in situations of strong winds or shear leading to a strong mixing in the Planetary Boundary Layer (PBL) [23], or aerosol events where the particulate load is very close to the ground, as in the smoke cases, in such events this assumption will be biased in the opposite sense. However, the high amount of data considered in this study lead us to think that the general atmospheric structure is not like the presented in these two cases.

As it is shown in table 3 the absolute value of the MBE is nearly the same for the GR-CP and the GR-AU layers, despite GR-AU being a wider layer. Taking into account how GRASP algorithm obtains the extinction profiles, it may be hypothesized that GR-AU layer should have a higher negative bias, because it counts with a larger amount of underestimated points in the integral to compensate the overestimated overlap region. However, the height difference among both layers is really small compared with the part of the profile where the compensation is distributed, the full profile reaches from the ground to $40 \mathrm{~km}$. Thus, what we are seeing here is a nearly constant overestimation introduce in the lower part for both layers.

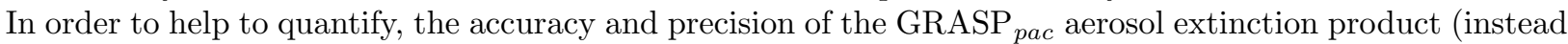
of the integrated value previously obtained) in each layer, the MBE and STD divided by the geometrical layer depth $\left(L_{D}\right)$ has been calculated (both values are shown in last columns of table 3 ). The accuracy of aerosol extinction product of GRASP ${ }_{p a c}$ for the lower layers (GR-CP and GR-AU) varies between $19 \mathrm{Mm}^{-1}(30 \%)$ at $440 \mathrm{~nm}$ and $9 \mathrm{Mm}^{-1}(35 \%)$ at $675 \mathrm{~nm}$. On the other hand, the higher layers (CP-TOA and AU-TOA) present the highest accuracy with values varying between $-0.83 \mathrm{Mm}^{-1}(40 \%)$ at $1020 \mathrm{~nm}$ and $-0.31 \mathrm{Mm}^{-1}(21 \%)$ at $1020 \mathrm{~nm}$. Due to the short integration performed for the intermediate layer (CP-AU), no bias was found in two wavelengths 675 and $1020 \mathrm{~nm}$, but, a value of $4.5 \mathrm{Mm}^{-1}(13 \%)$ at $440 \mathrm{~nm}$ was obtained. In the case of the precision a similar behaviour can be found, the lower layers present a higher dispersion with values between 24 $\mathrm{Mm}^{-1}(38 \%)$ at $440 \mathrm{~nm}$ and $10 \mathrm{Mm}^{-1}(50 \%)$ at $1020 \mathrm{~nm}$; and the precision of the higher layers ranges from $0.77 \mathrm{Mm}^{-1}(25 \%)$ at $440 \mathrm{~nm}$ and $0.5 \mathrm{Mm}^{-1}(41 \%)$ at $1020 \mathrm{~nm}$. For the intermediate layer the precision varies between $25 \mathrm{Mm}^{-1}(68 \%)$ at $440 \mathrm{~nm}$ and $15 \mathrm{Mm}^{-1}(59 \%)$ at $1020 \mathrm{~nm}$. If an average of all the layers is performed in each wavelength, the highest accuracy was found at $1020 \mathrm{~nm}$ with a $\mathrm{MBE} / L_{D}$ of $4.3 \mathrm{Mm}^{-1}(30 \%)$ and the lowest accuracy corresponds to $440 \mathrm{~nm}$ with a $\mathrm{MBE} / L_{D}$ of $6.8 \mathrm{Mm}^{-1}(27 \%)$; the precision presents a similar behaviour, the highest precision is corresponds to a $\operatorname{STD} / L_{D}$ of $8.6 \mathrm{Mm}^{-1}(48 \%)$ at $1020 \mathrm{~nm}$, and the smallest one corresponds to a STD $/ L_{D}$ of $13 \mathrm{Mm}^{-1}(42 \%)$ at $440 \mathrm{~nm}$.

Previously, [13] performed sensitivity tests with synthetic profiles. The averaged MBE in the aerosol extinction obtained by [13] for all synthetic scenarios for $440 \mathrm{~nm}$ were $13 \%$, and $8 \%$ for $1020 \mathrm{~nm}$ (these results were not published but the authors provided us). On the other hand, these authors obtained STD values of 
$37 \%$ and $17 \%$ for $440 \mathrm{~nm}$ and $1020 \mathrm{~nm}$, respectively. Comparing these values with the ones shown in table 3, it can be seen how the results obtained by [13] are lower. This is the expected behaviour, as in the sensitivity studies only inconsistencies of the inversion procedure are accounted, and in the real study instrument and atmospheric inconsistencies are also included. Furthermore, the higher AOD at $440 \mathrm{~nm}$ used in the synthetic scenarios explains also why the relative values of MBE and STD are smaller than the calculated ones in this study.

\subsection{Dependence of $\triangle \mathrm{IAE}$ and AOD on IAE}

The first dependence evaluation included in this study is the dependence of the GRASP pac $_{\text {p }}$ performance with the total aerosol load. Thus, figure 4 shows the averaged $\triangle \mathrm{IAE}$,for several AOD bins (measured from Granada AERONET photometer: $\mathrm{AOD}_{\mathrm{AER}-\mathrm{GR}}$ ). It can be seen how all $\triangle \mathrm{IAE}$ corresponding to the higher layers are negative, and those of lower layers are positive. The absolute value of bias in all the layers is higher when the aerosol load in Granada increases except in CP-AU. However, all the $\triangle \mathrm{IAE}$ data points in the CP-AU layer are positive as the rest of the lower layers, which can be caused due to the short length of this layer $(\sim 680 \mathrm{~m})$. This $\triangle \mathrm{IAE}$ dependence on AOD is coherent with our hypothesis, because the larger the aerosol load is in all the column over Granada, a higher concentration in the ACL level is expected. Thus, a higher difference in IAE in ACL layer is expected, leading to this increasing bias with the Granada AOD. Although this absolute difference with respect to the $\mathrm{AOD}_{\mathrm{AER}-\mathrm{GR}}$ value is higher, the relative difference in regard to the AERONET value is not very significant. Furthermore, the higher AOD values correspond to outbreaks which normally lead to higher inhomogeneities in the atmosphere, thus a higher uncertainty is also expected.

As can be seen in figure 4, the $\triangle \mathrm{IAE}$ dispersion is higher for the lower wavelengths. The reasons have been explained earlier, the higher aerosol extinction at these wavelengths and the considerable spectral distance from ceilometer signal used by GRASP ${ }_{p a c}$ at $1064 \mathrm{~nm}$.

On the other hand, the performance of GRASP $\mathrm{Pac}_{\text {pac }}$ has been analyzed as a function of the aerosol load present in each intermediate layer in order to see the effect of the aerosol in each layer on its IAE values. Figure 5 shows the $\triangle \mathrm{IAE}$ averages for different AERONET IAE bins at each layer. The results are similar to those of the previous case: negative bias in the higher part of the profile and positive bias in the lower part. Also as in the previous case, the absolute value of bias increases with the IAE of each layer. In CP-AU layer the values of $\triangle \mathrm{IAE}$ for an IAE less than 0.05 are centered at zero, which points out no bias for this data in this layer. This apparent lack of bias can be caused by the short integration made in this layer, the GRASP compensation of the lower layer overestimation is distributed along the whole column, so the accumulated bias introduced in this thin layer is not enough to be appreciated. This is in agreement with the earlier result where we obtained the same bias between the layers of GR-CP and GR-AU.

\subsection{Dependence of $\triangle \mathrm{IAE}$ on aerosol size}

Hitherto the analysis of data has been focused in the aerosol load, integrated in all the column or in its distribution through the different layers, but not in the aerosol type which could affect the performance of GRASP $_{\text {pac }}$ IAE product. In order to study the aerosol type impact on this performance, the averaged $\triangle \mathrm{IAE}$ values for various Ångström Exponent bins (obtained from Granada AERONET photometer) are shown in figure 6, since Ångström Exponent helps to discern between the aerosol size. As in all the results showed, in figure 6 a positive bias of the $\triangle \mathrm{IAE}$ value for the lower layers is observed, and a positive one for the higher levels, but not for the CP-AU layer. In this representation can be observed how the performance of IAE from GRASP $_{p a c}$ is worse for lower Angström Exponent values (coarse particles mainly). When the $\triangle \mathrm{IAE}$ show the higher absolute values but also the highest standard deviation for all layers. These IAE differences and standard deviation values are significantly reduced for the higher values of Ångström Exponent (fine particles). A possible explanation of why the bias is also increased for the lower values of the Ångström Exponent is that these situations are normally associated with desert dust events where the aerosol load tend to be also higher, hence, the behaviour is similar to the obtained before for high aerosol loads.

Once the evaluation of $\triangle \mathrm{IAE}$ as function of the Ångström Exponent in the whole column has been done, the aerosol size variations between the limits of the different layers is going to be considered. The single-wavelength character of the ceilometer implies assuming the same intensive aerosol properties in the inversion along all the column; however with AERONET sun/sky photometers an evaluation of them in the different layers can be done. Thus, in order to study the uncertainty introduced by this assumption, figure 7 presents the $\triangle \mathrm{IAE}$ averaged values as function of the AERONET Ångström Exponent difference $(\Delta \AA)$ of the referred layers; note that the horizontal axes are different for the lower layers. Once again the results of figure 7 showed a positive bias of the IAE value for the lower layers and a negative one for the higher levels, but this situation is different. In the higher layers and in the case of the intermediate one (CP-AU), the behaviour is in agreement with the expectations, the IAE values present a higher concordance with the AERONET ones when the Ångström 
Exponent is more similar between the layers, this means that there has not been any change of aerosol type along the column.

If the aerosol type present in higher layers differs from the assumed in Granada a higher uncertainty is expected. In addition, the main explanation for the bias presented here was based in assuming a maximum level of aerosol concentration not in the ground level, but in an intermediate height of the PBL. This means that the bias was directly related with a incorrect election of the overlap reference level to refill the ACL layer, based on a "too high" aerosol concentration in this reference height in comparison with the rest of the ACL. However, this bias also could be caused by some aerosol intensive properties of the overlap reference layer are not truly representative of the ACL layer.

Although aerosol optical properties could be well represented in all the profile, if the aerosol size is significantly different in the overlap reference level it will lead to a bias. In urban areas, as Granada, the PBL (Planetary Boundary Layer) is commonly dominated for urban pollution [14], while very different aerosol types can be found in the higher levels, especially in desert dust events. Thus, we could expect that this uncertainty in the microphysical properties of the aerosol could be the responsible of the bias. Nevertheless, in figure 7 it can be seen how in the lower layers (GR-CP and GR-AU) the most discrepant IAE values correspond with the events where the Ångström Exponent is more stable between layers, $\Delta \AA$ bins -0.2 to 0 and 0 to 0.2 . The error in the determination of the aerosol likely seems to compensate the overestimation of the lower layers leading to a better IAE value. This result discards the alternative hypothesis for explaining the lower layer overestimation based only in a improper election of the aerosol size of the ACL layer.

The single component atmosphere assumption cannot be the only source of this bias. So, the other only source of uncertainty specifically related with the lower part of the profile is the ACL assumption. As it has been shown, the hypothesis of the higher aerosol concentration in this level than in the ground could explain the results obtained here.

\subsection{Assumed atmospheric homogeneity}

One of the main assumptions made at the beginning of this study is the homogeneity of the atmosphere measured by the three sun/sky photometers and the ceilometer of Granada. This section includes an analysis of the effect of the possible inhomogeneities between the three stations.

Following geometric considerations, the overlap between the volume measured by the almucantar of Granada sun/sky photometer and the direct measurement of Cerro_Poyos and Albergue_UGR instruments can be calculated. It should be noted that even the AERONET almucantar itself implies a significant degree of homogeneity at high altitudes. If the three sun/sky photometers are pointing to Granada direction (in the afternoon), the three measured volumes start to overlap $\simeq 1 \mathrm{Km}$ over Cerro_Poyos station for the better case of Solar Zenith Angle equal to $80^{\circ}$, which can be seen as reasonable due to the scarce PBL of the clear mountain region. However, for the lowest SZA used in GRASP pac $_{1},\left(40^{\circ}\right)$, this overlap is not produced until $\simeq 10 \mathrm{Km}$ over Cerro_Poyos station. Furthermore, when the three sun/sky photometers are pointing to the mountain area (in the morning) no overlap at all is achieved among the three measurements. This lack of overlap, and the fact that the value of the mountain PBL AOD, despite being scarce, is expected to be higher than the AOD of the same layer over the city of Granada could lead to explain part of the bias observed in this study.

Due to the specific geographical situation of the measurement sites included in this study, the "mounting venting" effect [24] needs to be taken into consideration. This effect implies that the nearby mountain slope to the polluted urban PBL over Granada city produces an injection of pollutants and another kind of aerosols into the free troposphere. This mountain chimney effect increases the time that particulate matter spends in the atmosphere, and eventually could lead to inhomogeneities if these particles are only measured by CP and AU photometers, which will lead to a bias with a similar structure that the one found here. Nevertheless, if the mountain venting effect produces an aerosol outbreak over the free troposphere which can only be measured by the Granada sun/sky photometer, then, the bias will have an opposite sign leading to a compensation of the one observed in this study.

The other main possible reason behind the observed bias is not related with the measurement geometry, but with the variation of the PBL height [25], and correspondingly the level of maximum aerosol concentration. The solar diurnal cycle leads to a thermal expansion of the atmosphere, leading also to a diurnal cycle in the PBL height. The smaller SZA angles (absolute value) lead to deeper PBL, increasing the level of maximum aerosol concentration closer to the overlap reference level which will produce a larger bias.

For all the reasons exposed above, a variation of the AOD difference with the SZA could be expected. As it has been already mentioned, the expected bias would be larger in the afternoons (positive SZA) because the sun/sky photometers measure part of the urban PBL over Granada with a higher AOD. However, for negative SZA values, sun/sky photometers are measuring part of the clearer atmosphere of Sierra-Nevada leading to a smaller AOD and correspondingly a smaller bias.

In figure 8 is represented the $\triangle \mathrm{IAE}$ averaged for different SZA bins corresponding to when each measurement was taken, considering as negative angles the ones corresponding to the morning, and positives for the ones 
in the afternoon. Five bins from $-80^{\circ}$ to $-40^{\circ}$ and five bins for 40 to $80^{\circ}$ have been selected. No significant dependency with the SZA can be seen in any layer or any wavelength. As in the former cases the lower layers have a positive bias, in contrast with the higher ones in which this bias is negative.

The results concerning the Solar Azimuth Angle are not shown here but the tendencies observed are almost identical than in the case of the SZA. Any variation on the bias cannot be inferred from Solar Azimuth nor Zenith angle representations in any layer or wavelength.

In order to study the reliability of the homogeneity assumed here, an analysis of the AERONET AOD at 440 $\mathrm{nm}$ and AERONET Ångström Exponent 440-870 nm also averaged for different SZA bins for the three stations have been performed (not shown). The variations with SZA, the mean value and the standard deviation of the three stations for both magnitudes present a high correlation, and no significant evidence of strong inhomogeneities can be found.

Giving the scarce variation of $\triangle \mathrm{IAE}$ with SZA and Solar Azimuth Angle, and the agreement of the AOD and Ångström Exponent series of the three stations independently, a reasonable homogeneity among the measurements of the four instruments (the three sun/sky photometers and the ceilometer) has been found. The variation of the PBL height during the day and the different pointing directions of sun/sky photometers seems not to have a high impact in the discrepancy among GRASP ${ }_{p a c}$ IAE product and AERONET IAE, either in its uncertainty, in comparison with the ACL approximation that is being assumed. However the horizontal distance between the three sun/sky photometers, and the different nature of the PBL corresponding to each of them, could partially explain the obtained bias.

\subsection{Other possible bias sources}

Hitherto several causes of the bias have been analysed in detail. However, due to the complex nature of the presented methodologies, a high amount of different factors with a possible influence in the obtained bias remain out of this study.

As it has been commented before the election of the overlap reference level, and in consequence the depth of the ACL, plays an important role in the bias obtained in this study. A dependency with the temperature of the overlap height of the Lufft ceilometer were previously reported by [26]. The correction proposed by these authors for the overlap height variation of the ceilometer with temperature could help to reduce the observed bias. Moreover, as it has been shown by [27] the CHM-15k ceilometer in comparison with an atmospheric LiDAR shows an increment of $20 \%$ of the signal at 250 meters (the overlap reference layer) due to an incorrect overlap correction of the manufacturer. Thus, this effect will contribute to the observed bias between the lower and upper layers.

On the other hand, the self uncertainties in the retrieval of intensive aerosol properties of GRASP pac $_{\text {inversion }}$ could provide significant inconsistencies. Uncertainties on the retrieved LiDAR ratio of aerosol could be the responsible for part of the bias. If this magnitude is higher than the real one in the ACL layer, it will lead to an extinction overestimation. This situation could happen, for example, when dust outbreak reaches the lower layer. However the measured values of LiDAR ratio of urban aerosol are one of the highest between all aerosol types [28][29]. Thus, assuming a different aerosol type than the urban one in the whole column will lead to an underestimation of the aerosol extinction instead of the overestimation observed here.

\section{Granada Extinction Vertical profiles}

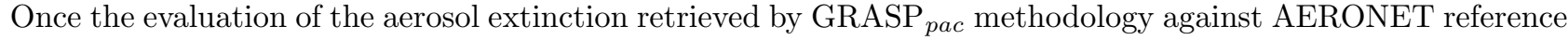
data, where possible influences in the retrieved product have been analysed, the IAE averaged values for the entire considered period, November of 2012 to December of 2017, of each considered layer has been obtained using both GRASP ${ }_{p a c}$ and AERONET data. The averaged seasonal IAE values for the five different layers can be found for all wavelengths available in table 4 and 5, for AERONET and GRASP pac $_{\text {methodologies, }}$ respectively. Such as the rest of this work only positive IAE values has been taken into account to calculate these averaged values. No data for the winter periods for all layers involving Albergue_UGR station is available because photometers are not operative in these places due to snowfall in this season. This problem is not present in GRASP ${ }_{p a c}$ methodology because the ceilometer profiles have been integrated only with the Granada sun/sky photometer. Due to the quality assurance criteria in the data selection for this study all the average IAE values

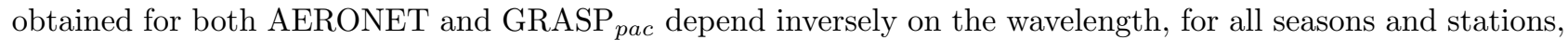
except for the AERONET Autumn value at $870 \mathrm{~nm}$.

As expected, the mean IAE values for $\mathrm{GRASP}_{p a c}$, showed in table 5, depend directly on the layer depth. All GR-CP values are higher than GR-AU, and the same issue occurs with CP-TOA and AU-TOA, due to the larger integration performed in GR-AU and in CP-TOA. On the other hand, this is not the case for AERONET IAE values. For this methodology IAE is not always directly proportional to the layer depth, in Autumn and for the annual mean GR-CP IAE value is higher than GR-AU. This incoherence is explained by the different 
sample of days included in the average of each layer. If the same mean is calculated, but only taking into account measurements when data is available in the three AERONET stations (not shown), this artifact disappears. This result supports one of the initial assumptions of this study, the horizontal homogeneity between the three stations considered for this study.

Figure 9 shows the seasonal and annual mean vertical extinction profiles, obtained from previously averaged daily averaged; the shaded area corresponds to the the standard deviation of each point. Note that the standard deviation of the annual profile is significantly lower compared with the rest of the seasons, because it has been calculated as the mean of the four seasons instead of the average of all profiles. Spring and Autumn profiles do not present any singular behaviour; both present a higher extinction and standard deviation in the lower layers. This is the expected behaviour, because the main aerosol sources of this area are located in the ground [14]. However, the location of the selected stations implies the occasional impact of elevated dust or biomass burning outbreaks which lead to the some standard deviation maximums in the upper levels, especially in Summer. Winter presents the highest peak of aerosol extinction at $440 \mathrm{~nm}$ with the highest wavelength dependency in the lower part of the profile. This must be caused by the increased emission of heating systems and the higher urban traffic typical of this time of the year [14], furthermore the small size of this aerosols explain the high Ångström exponent 440-870 (wavelength dependency) of the winter lower layers. There is an unusual high standard deviation between 1500 and 4000 meters caused by two extremely strong Saharan dust outbreaks in 2016 [12] and 2017 [30], both in February. However at the sight of the mean extinction value at these levels, a very clear atmosphere can be found normally in these heights. On the other hand, in Summer the upper levels of the profile, from 1500 to 4500 meters approximately, present the highest extinction for all seasons. This elevated extinction values are caused by Saharan dust outbreaks which are very often in Granada area in Summer [15]. The contribution of these outbreaks to the PBL also explain the high extinction of this season in the lower levels, and the larger size of dust particles is the responsible of the smaller wavelength dependency of the Summer profile in comparison with the rest of the seasons.

Other authors [21] also perform this type of long-term average of extinction vertical profiles. Common features can be observed in both data sets. An exponential decay from the top of the PBL with height also can bee seen in $[21]$ for all seasons. Furthermore, the highest variability in the upper layers is found in Summer in Granada and in Montsec.

Finally, all the profiles shown in figure 9 present a strange behaviour near to $250 \mathrm{~m}$ a.g.l., for the two lowest

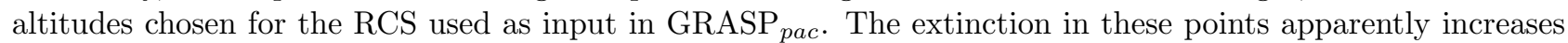
and, after that, strongly decreases just in the point that is assumed equal to the ground. This behaviour is

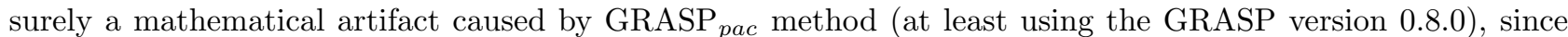
the RCS values used as input does not show this peak. In addition these peaks have been also observed in other locations with this methodology but not in [21] at Montsec where the ACL assumption was not used (ceilometer is $760 \mathrm{~m}$ below sun/sky photometer). These results points out that the artifact shown in Figure 9 is likely caused by GRASP ${ }_{p a c}$ in order to fit the aerosol extinction in the lowest heights with the ACL assumption. This artifact could be at least part of the bias values found in this work.

\section{Conclusions}

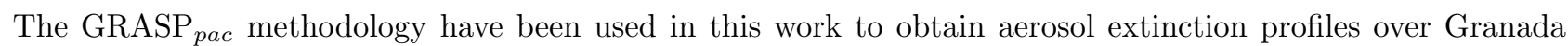
using ceilometer and sun/sky photometer measurements as input in the GRASP code. The retrieved extinction profles have been integrated in different layers in order to evalaute the accuracy and uncertainty of GRASP ${ }_{p a c}$ products using as reference the AOD measurements at three AERONET stations located at different altitudes. Despite of the uncertainties arising from the method itself, the different nature and operative wavelengths of the ceilometer and the sun/sky photometers, and the different composition of the real atmosphere among the stations, GRASP ${ }_{p a c}$ method has been proved as useful in the retrieval of vertical aerosol extinction profiles starting from the ceilometer range corrected signal and the almucantar and AOD measurements from AERONET sun/sky photometers. The uncertainty showed by this methodology is in the range of uncertainty of the sun/sky photometers used.

However some discrepancies have been found among GRASP pac $_{\text {and }}$ aERONET data. The mean bias error (MBE \pm standard deviation), calculated as GRASP pac - AERONET, on IAE (Integrated Aerosol Extinction) of the upper layers is $-0.03 \pm 0.03(32 \pm 31 \%)$ at $440 \mathrm{~nm}$ and $-0.01 \pm 0.02(28 \pm 36 \%)$ at $1020 \mathrm{~nm}$; and for the lower layers $0.02 \pm 0.03(30 \pm 39 \%)$ at $440 \mathrm{~nm}$ and $0.02 \pm 0.02(47 \pm 55 \%)$ at $1020 \mathrm{~nm}$ were found.

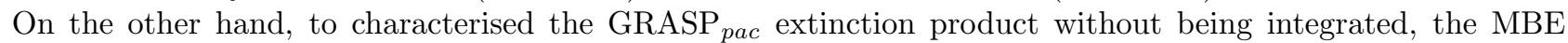
and standard deviation divided by the geometrical layer depth $\left(L_{D}\right)$ were analysed $\left(\mathrm{MBE} / L_{D} \pm\right.$ standard deviation $\left(L_{D}\right)$. Thus, for the extinction, the most accurate wavelength is $1020 \mathrm{~nm}$ with a value of $4.3 \pm 8.6$ $\mathrm{Mm}^{-1}(30 \pm 48 \%)$; the least accurate wavelength is $440 \mathrm{~nm}$ with a value of $6.8 \pm 13.3 \mathrm{Mm}^{-1}(27 \pm 42 \%)$. In general GRASP ${ }_{p a c}$ underestimates the aerosol extinction at high altitudes and overestimates this extinction

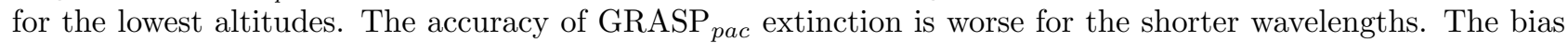


between the lower and higher parts of the profile has been found persistently in all the considered data set, which gets increased with the aerosol load. It has been provided a possible explanation of this bias: the ACL (Assumed Constant Lower) layer overestimates the real aerosol load, which is consistent with all the results obtained in this study. Furthermore, with the different analysis made here, the aerosol type, or the change of it along the column have been discarded as main sources of bias by analysing the Ångström exponent for the Granada station and the difference of Ångström exponent between each layer. However, the possible difference in the atmospheric volume being measured by the sun/sky photometers in the different moments of the day may lead to explain part of the bias observed here. In addition, a mathematical artifact in GRASP pac likely caused by the ACL assumption could be also responsible of this bias.

Furthermore, an annual and seasonal average of IAE values, but also extinction vertical profiles have been calculated. Constantly decreasing profiles (from the upper limit of the planetary boundary layer to the top of the atmosphere) and a high variability have been found for all seasons, specially in the lower part of the profile. This behaviour can be explained taking into account that the main aerosol sources at Granada are located near to the ground. The largest aerosol load over Granada corresponds to Summer when Saharan dust outbreaks are frequent.

GRASP $_{\text {pac }}$ seems to be useful for obtaining aerosol extinction vertical profiles, at least integrated in several layers. The mean values obtained here could lead to a better understanding of the aerosol over Granada in another climatological studies of this city.

\section{Acknowledgements}

This work was supported by the Andalusia Regional Government (project P12-RNM-2409) and by the "Consejería de Educación" of "Junta de Castilla y León" (project VA100U14); the Spanish Ministry of Economy and Competitiveness under the projects, CMT2015-66742-R, CGL2016-81092-R, "Juan de la Cierva-Incorporación" program (FIJCI-2016-30007) and CGL2017-90884-REDT; and the European Union's Horizon 2020 research and innovation program through project ACTRIS-2 (grant agreement No 654109). The authors acknowledge ANRT by the CIFRE program 2019/0003. The authors thankfully acknowledge the FEDER program for the instrumentation used in this work. COST Action TOPROF (ES1303), supported by COST (European Cooperation in Science and Technology), is also acknowledged. The authors acknowledge the use of GRASP inversion algorithm (www.grasp-open.com), and also thank to D. Fuertes, A. Lopatin and O. Dubovik for their feedback in the use of GRASP. The authors greatly acknowledge the help of the Sierra Nevada National Park in the maintenance and access to the Cerro de los Poyos station.

\section{References}

[1] K Willeke and P A Baron. Aerosol measurement. Principles, techniques and applications. Van, 1993.

[2] S E Bauer and S Menon. Aerosol direct, indirect, semidirect, and surface albedo effects from sector contributions based on the ipcc ar5 emissions for preindustrial and present-day conditions. Journal of Geophysical Research: Atmospheres, 117(D1), 2012.

[3] B N Holben, T F Eck, I Slutsker, D Tanre, JP Buis, A Setzer, E Vermote, J A Reagan, YJ Kaufman, T Nakajima, et al. Aeronet - a federated instrument network and data archive for aerosol characterization. Remote sensing of environment, 66(1):1-16, 1998.

[4] O Dubovik, B Holben, T F Eck, A Smirnov, Y J Kaufman, M D King, D Tanré, and I Slutsker. Variability of absorption and optical properties of key aerosol types observed in worldwide locations. Journal of the atmospheric sciences, 59(3):590-608, 2002.

[5] O Dubovik, A Sinyuk, T Lapyonok, B N Holben, M Mishchenko, P Yang, T F Eck, H Volten, O Munoz, B Veihelmann, et al. Application of spheroid models to account for aerosol particle nonsphericity in remote sensing of desert dust. Journal of Geophysical Research: Atmospheres, 111(D11), 2006.

[6] J D Klett. Stable analytical inversion solution for processing lidar returns. Applied Optics, 1982.

[7] G Pappalardo, A Amodeo, A Apituley, A Comeron, V Freudenthaler, H Linné, A Ansmann, J Bösenberg, G D'Amico, I Mattis, L Mona, U Wandinger, V Amiridis, L Alados-Arboledas, D Nicolae, and M Wiegner. Earlinet: towards an advanced sustainable european aerosol lidar network. Atmospheric Measurement Techniques, 2014.

[8] O Dubovik, T Lapyonok, P Litvinov, M Herman, D Fuertes, F Ducos, A Lopatin, A Chaikovsky, B Torres, Y Derimian, et al. Grasp: a versatile algorithm for characterizing the atmosphere. SPIE Newsroom, 25, 2014 . 
[9] A Lopatin, O Dubovik, A Chaikovsky, Ph Goloub, T Lapyonok, D Tanré, and P Litvinov. Enhancement of aerosol characterization using synergy of lidar and sun-photometer coincident observations: the garrlic algorithm. Atmospheric Measurement Techniques, 6(8):2065, 2013.

[10] J A Benavent-Oltra, R Román, M J Granados-Muñoz, D Pérez-Ramírez, P Ortiz-Amezcua, C Denjean, A Lopatin, H Lyamani, B Torres, J L Guerrero-Rascado, et al. Comparative assessment of grasp algorithm for a dust event over granada (spain) during charmex-adrimed 2013 campaign. Atmospheric Measurement Techniques, 10(11):4439, 2017.

[11] M Wiegner, F Madonna, I Binietoglou, R Forkel, A Gasteiger, J Geiß, G Pappalardo, K Schäfer, and Thomas W. What is the benefit of ceilometers for aerosol remote sensing? an answer from earlinet. Atmos. Meas. Tech., 2014.

[12] A Cazorla, J A Casquero-Vera, R Roman, J L Guerrero-Rascado, C Toledano, V E Cachorro, J A Orza, M L Cancillo, A Serrano, G Titos, et al. Near real time processing of ceilometer network data: characterizing an extraordinary dust outbreak over the iberian peninsula. Atmospheric Chemistry and Physics, 2017.

[13] R Román, J A Benavent-Oltra, J A Casquero-Vera, A Lopatin, A Cazorla, H Lyamani, C Denjean, D Fuertes, Daniel Pérez-Ramírez, B Torres, et al. Retrieval of aerosol profiles combining sunphotometer and ceilometer measurements in grasp code. Atmospheric Research, 204:161-177, 2018.

[14] G Titos, I Foyo-Moreno, H Lyamani, X Querol, A Alastuey, and L Alados-Arboledas. Optical properties and chemical composition of aerosol particles at an urban location: An estimation of the aerosol mass scattering and absorption efficiencies. Journal of Geophysical Research: Atmospheres, 117(D4), 2012.

[15] A Valenzuela, F J Olmo, H Lyamani, M Antón, G Titos, A Cazorla, and L Alados-Arboledas. Aerosol scattering and absorption angström exponents as indicators of dust and dust-free days over granada (spain). Atmospheric Research, 154:1-13, 2015.

[16] Jenoptik. Chm15k - nimbus ceilometer user manual. revision p0. 2013.

[17] S Kotthaus, E O'Connor, C Münkel, C Charlton-Perez, M Haeffelin, A M Gabey, and C S B Grimmond. Recommendations for processing atmospheric attenuated backscatter profiles from vaisala cl31 ceilometers. Atmospheric Measurement Techniques, 9(8):3769-3791, 2016.

[18] Z Dong, Z Li, X Yu, M Cribb, X Li, and J Dai. Opposite long-term trends in aerosols between low and high altitudes: a testimony to the aerosol-pbl feedback. Atmos. Chem. Phys., 17(12):7997-8009, 2017.

[19] D Tanré, Y J Kaufman, B N e al Holben, B Chatenet, A Karnieli, F Lavenu, L Blarel, O Dubovik, L A Remer, and A Smirnov. Climatology of dust aerosol size distribution and optical properties derived from remotely sensed data in the solar spectrum. Journal of Geophysical Research: Atmospheres, 106(D16):18205-18217, 2001.

[20] B Torres, O Dubovik, D Fuertes, G Schuster, V E Cachorro, T Lapyonok, P Goloub, L Blarel, A Barreto, M Mallet, C Toledano, and D Tanré. Advanced characterization of aerosol properties from measurements of spectral optical depth using the grasp algorithm. Atmos. Meas. Tech. Discuss., 40, 2016.

[21] Gloria Titos, Marina Ealo, Roberto Román, Alberto Cazorla, Yolanda Sola, Oleg Dubovik, Andrés Alastuey, and Marco Pandolfi. Retrieval of aerosol properties from ceilometer and photometer measurements: long-term evaluation with in situ data and statistical analysis at montsec (southern pyrenees). Atmospheric Measurement Techniques, 12(6):3255-3267, 2019.

[22] C Pérez, J M Nickovic, and Baldasano, M Sicard, F Rocadenbosch, and V E Cachorro. A long saharan dust event over the western mediterranean: Lidar, sun photometer observations, and regional dust modeling. Journal of Geophysical Research, 111(D115), 2006.

[23] J F Price, C NK Mooers, and J C Van Leer. Observation and simulation of storm-induced mixed-layer deepening. Journal of Physical Oceanography, 8(4):582-599, 1978.

[24] Ying Chen, Chunsheng Zhao, Qiang Zhang, Zhaoze Deng, Mengyu Huang, and Xincheng Ma. Aircraft study of mountain chimney effect of beijing, china. Journal of Geophysical Research: Atmospheres, 114(D8), 2009 .

[25] B Medeiros, A Hall, and B Stevens. What controls the mean depth of the pbl? Journal of climate, 18(16):3157-3172, 2005. 
[26] H Maxime, Y Poltera, and A Haefele. An empirical method to correct for temperature-dependent variations in the overlap function of chm15k ceilometers. Atmospheric Measurement Techniques, 9(7):2947-2959, 2016.

[27] Y Jin, N Sugimoto, A Shimizu, T Nishizawa, K Kai, K Kawai, A Yamazaki, M Sakurai, and H Wille. Evaluation of ceilometer attenuated backscattering coefficients for aerosol profile measurement. Journal of Applied Remote Sensing, 12(4):042604, 2018.

[28] C Cattrall, J Reagan, K Thome, and O Dubovik. Variability of aerosol and spectral lidar and backscatter and extinction ratios of key aerosol types derived from selected aerosol robotic network locations. Journal of Geophysical Research: Atmospheres, 110(D10), 2005.

[29] S P Burton, R A Ferrare, C A Hostetler, J W Hair, R R Rogers, M D Obland, C F Butler, A L Cook, D B Harper, and K D Froyd. Aerosol classification using airborne high spectral resolution lidar measurementsmethodology and examples. Atmospheric Measurement Techniques, 5(1):73-98, 2012.

[30] A J Fernández, M Sicard, M J Costa, J L Guerrero-Rascado, J L Gómez-Amo, F Molero, R Barragán, D Bortoli, A E Bedoya-Velásquez, M P Utrillas, et al. Extreme, wintertime saharan dust intrusion in the iberian peninsula: Lidar monitoring and evaluation of dust forecast models during the february 2017 event. Atmospheric Research, 228:223 - 241, 2019. 


\section{Tables}

Table 1: Number of valid IAE values in each considered layer, and the number of negative ones discarded in the filtering.

\begin{tabular}{cccc}
\hline Layer & Valid Data & Negative IAE (\%) & Negative IAE within uncertainty (\%) \\
\hline \hline GR-CP & 2870 & $87(3.03)$ & $51(1.77)$ \\
GR-AU & 1394 & $148(10.62)$ & $49(3.52)$ \\
CP-AU & 659 & $306(46.43)$ & $288(43.7)$ \\
CP-TOA & 3007 & $12(0.40)$ & $4(0.13)$ \\
AU-TOA & 1577 & $4(0.25)$ & $2(0.13)$ \\
\hline
\end{tabular}

Table 2: Fitting parameters of the least square fit shown in figure $2\left(\mathrm{y}=\mathrm{bx}+y_{0}\right)$, its the determination coefficient $\left(r^{2}\right)$ and the number of points included in each layer $(\mathrm{N})$, for the two selected wavelengths 440 and $1020 \mathrm{~nm}$.

\begin{tabular}{llllll}
\hline$\lambda=440 n m$ & CP-TOA & AU-TOA & GR-CP & GR-AU & CP-AU \\
\hline \hline $\mathrm{N}$ & 2990 & 1569 & 2867 & 1394 & 773 \\
$\mathrm{~b}$ & 0.86 & 0.79 & 0.83 & 0.98 & 0.66 \\
$y_{0}$ & -0.01 & -0.01 & 0.03 & 0.02 & 0.01 \\
$r^{2}$ & 0.92 & 0.83 & 0.64 & 0.68 & 0.57 \\
\hline
\end{tabular}

\begin{tabular}{llllll}
\hline$\lambda=1020 \mathrm{~nm}$ & CP-TOA & AU-TOA & GR-CP & GR-AU & CP-AU \\
\hline \hline $\mathrm{N}$ & 2990 & 1569 & 2867 & 1394 & 773 \\
$\mathrm{~b}$ & 0.83 & 0.79 & 0.70 & 1.12 & 0.71 \\
$y_{0}$ & 0.00 & -0.01 & 0.01 & 0.01 & 0.01 \\
$r^{2}$ & 0.96 & 0.90 & 0.46 & 0.83 & 0.74 \\
\hline
\end{tabular}

Table 3: Statistical magnitudes calculated for $\triangle \mathrm{IAE}$, including Mean Bias Error (MBE), standard deviation, the number of $\triangle \mathrm{IAE}$ values smaller than the AERONET uncertainty $\left(\triangle \mathrm{IAE}<\sigma_{A E R}\right)$ and the MBE and STD divided by the geometrical layer depth $\left(L_{D}\right)$ in the selected layers for wavelengths 440, 675, 870 and $1020 \mathrm{~nm}$. Relative values in percentage are in parenthesis.

\begin{tabular}{|c|c|c|c|c|c|c|}
\hline Layer & $\lambda(\mathrm{nm})$ & $\mathrm{MBE}$ & STD & $\Delta \mathrm{IAE}<\sigma_{A E R}$ & $\mathrm{MBE} / L_{D}\left(\mathrm{Mm}^{-1}\right)$ & $\mathrm{STD} / L_{D}\left(\mathrm{Mm}^{-} 1\right)$ \\
\hline \multirow{4}{*}{ GR-CP } & 4440 & $0.022(30)$ & $0.028(38)$ & $2341(81)$ & $19(30)$ & $24(38)$ \\
\hline & 675 & $0.016(35)$ & $0.021(45)$ & $2054(72)$ & $14(35)$ & $18(45)$ \\
\hline & 870 & $0.012(32)$ & $0.019(49)$ & $2261(79)$ & $10(32)$ & $17(49)$ \\
\hline & 1020 & $0.014(44)$ & $0.019(59)$ & $2198(77)$ & $12(44)$ & $17(59)$ \\
\hline \multirow{4}{*}{ GR-AU } & 440 & $0.022(30)$ & $0.030(41)$ & $1078(77)$ & $12(30)$ & $16(41)$ \\
\hline & 675 & $0.017(35)$ & $0.021(43)$ & $940(67)$ & $9(35)$ & $11(43)$ \\
\hline & 870 & $0.017(41)$ & $0.020(50)$ & $982(70)$ & $9(41)$ & $11(50)$ \\
\hline & 1020 & $0.018(49)$ & $0.019(50)$ & $954(68)$ & $10(50)$ & $10(50)$ \\
\hline \multirow{4}{*}{$\mathrm{CP}-\mathrm{AU}$} & 440 & $0.003(13)$ & $0.017(68)$ & $645(98)$ & $4.5(13)$ & $25(68)$ \\
\hline & 675 & $0.000(0)$ & $0.012(61)$ & $605(92)$ & $0(0)$ & $17(61)$ \\
\hline & 870 & $0.002(11)$ & $0.012(65)$ & $604(92)$ & $3.0(11)$ & $18(65)$ \\
\hline & 1020 & $0.000(0)$ & $0.010(59)$ & $623(95)$ & $0(0)$ & $14.9(59)$ \\
\hline \multirow{4}{*}{ CP-TOA } & 440 & $-0.026(24)$ & $0.028(25)$ & $1309(44)$ & $-0.68(24)$ & $0.73(25)$ \\
\hline & 675 & $-0.016(21)$ & $0.021(28)$ & $1324(44)$ & $-0.42(21)$ & $0.55(28)$ \\
\hline & 870 & $-0.015(23)$ & $0.019(29)$ & $1459(49)$ & $-0.39(23)$ & $0.50(29)$ \\
\hline & 1020 & $-0.012(21)$ & $0.019(31)$ & $1731(58)$ & $-0.31(21)$ & $0.50(29)$ \\
\hline \multirow{4}{*}{ AU-TOA } & 440 & $-0.031(40)$ & $-0.029(37)$ & $574(36)$ & $-0.83(40)$ & $0.77(37)$ \\
\hline & 675 & $-0.017(32)$ & $0.021(41)$ & $695(44)$ & $-0.45(32)$ & $0.56(41)$ \\
\hline & 870 & $-0.021(40)$ & $0.020(38)$ & $524(33)$ & $-0.56(40)$ & $0.53(38)$ \\
\hline & 1020 & $-0.015(34)$ & $0.018(41)$ & $768(49)$ & $-0.40(34)$ & $0.48(41)$ \\
\hline
\end{tabular}


Table 4: Seasonal and annual IAE average values for AERONET methodology for all available wavelengths.

\begin{tabular}{|c|c|c|c|c|c|c|c|}
\hline Season & Layer & IAE $440 \mathrm{~nm}$ & IAE $675 \mathrm{~nm}$ & IAE $870 \mathrm{~nm}$ & IAE $1020 \mathrm{~nm}$ & Number of Days & Number of Data \\
\hline \multirow{5}{*}{ Winter } & GR-CP & $\overline{0.096}$ & 0.067 & 0.060 & 0.054 & 25 & 93 \\
\hline & GR-AU & - & - & - & - & 0 & 0 \\
\hline & CP-AU & - & - & - & - & 0 & 0 \\
\hline & CP-TOA & 0.112 & 0.083 & 0.077 & 0.069 & 26 & 102 \\
\hline & AU-TOA & - & - & - & - & 0 & 0 \\
\hline \multirow{5}{*}{ Spring } & GR-CP & 0.071 & 0.047 & 0.040 & 0.034 & 165 & 657 \\
\hline & GR-AU & 0.080 & 0.059 & 0.052 & 0.049 & 71 & 309 \\
\hline & CP-AU & 0.026 & 0.023 & 0.020 & 0.020 & 62 & 192 \\
\hline & CP-TOA & 0.115 & 0.082 & 0.075 & 0.062 & 167 & 687 \\
\hline & AU-TOA & 0.087 & 0.062 & 0.060 & 0.052 & 72 & 321 \\
\hline \multirow{5}{*}{ Summer } & GR-CP & 0.074 & 0.046 & 0.040 & 0.032 & 361 & 1911 \\
\hline & GR-AU & 0.086 & 0.061 & 0.051 & 0.046 & 162 & 745 \\
\hline & $\mathrm{CP}-\mathrm{AU}$ & 0.029 & 0.025 & 0.018 & 0.020 & 131 & 450 \\
\hline & CP-TOA & 0.117 & 0.080 & 0.070 & 0.062 & 360 & 1997 \\
\hline & AU-TOA & 0.102 & 0.070 & 0.070 & 0.058 & 164 & 811 \\
\hline \multirow{5}{*}{ Autumn } & GR-CP & 0.094 & 0.058 & 0.044 & 0.036 & 51 & 209 \\
\hline & GR-AU & 0.066 & 0.035 & 0.028 & 0.017 & 61 & 340 \\
\hline & $\mathrm{CP}-\mathrm{AU}$ & 0.016 & 0.011 & 0.006 & 0.008 & 6 & 17 \\
\hline & CP-TOA & 0.072 & 0.045 & 0.038 & 0.032 & 56 & 221 \\
\hline & AU-TOA & 0.043 & 0.021 & 0.023 & 0.019 & 64 & 445 \\
\hline \multirow{5}{*}{ Annual } & GR-CP & 0.085 & 0.054 & 0.046 & 0.038 & 602 & 2870 \\
\hline & GR-AU & 0.072 & 0.047 & 0.037 & 0.032 & 294 & 1394 \\
\hline & CP-AU & 0.025 & 0.021 & 0.021 & 0.025 & 199 & 659 \\
\hline & CP-TOA & 0.093 & 0.063 & 0.056 & 0.050 & 609 & 3007 \\
\hline & AU-TOA & 0.079 & 0.052 & 0.051 & 0.044 & 300 & 1577 \\
\hline
\end{tabular}

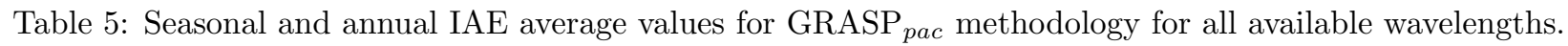

\begin{tabular}{|c|c|c|c|c|c|c|c|}
\hline Season & Layer & IAE $440 \mathrm{~nm}$ & IAE $675 \mathrm{~nm}$ & IAE $870 \mathrm{~nm}$ & IAE $1020 \mathrm{~nm}$ & Number of Days & Number of Profiles \\
\hline \multirow{5}{*}{ Winter } & GR-CP & 0.095 & 0.059 & 0.047 & 0.041 & \multirow{5}{*}{200} & \multirow{5}{*}{1117} \\
\hline & GR-AU & 0.111 & 0.070 & 0.056 & 0.049 & & \\
\hline & CP-AU & 0.015 & 0.011 & 0.009 & 0.008 & & \\
\hline & CP-TOA & 0.073 & 0.049 & 0.040 & 0.036 & & \\
\hline & AU-TOA & 0.058 & 0.038 & 0.031 & 0.028 & & \\
\hline \multirow{5}{*}{ Spring } & GR-CP & 0.093 & 0.059 & 0.047 & 0.041 & \multirow{5}{*}{256} & \multirow{5}{*}{1383} \\
\hline & GR-AU & 0.117 & 0.074 & 0.060 & 0.052 & & \\
\hline & $\mathrm{CP}-\mathrm{AU}$ & 0.024 & 0.016 & 0.013 & 0.012 & & \\
\hline & CP-TOA & 0.085 & 0.059 & 0.050 & 0.045 & & \\
\hline & AU-TOA & 0.061 & 0.043 & 0.037 & 0.033 & & \\
\hline \multirow{5}{*}{ Summer } & GR-CP & 0.097 & 0.067 & 0.056 & 0.051 & \multirow{5}{*}{417} & \multirow{5}{*}{2862} \\
\hline & GR-AU & 0.128 & 0.089 & 0.076 & 0.068 & & \\
\hline & $\mathrm{CP}-\mathrm{AU}$ & 0.032 & 0.022 & 0.019 & 0.018 & & \\
\hline & CP-TOA & 0.115 & 0.085 & 0.075 & 0.068 & & \\
\hline & AU-TOA & 0.084 & 0.063 & 0.055 & 0.051 & & \\
\hline \multirow{5}{*}{ Autumn } & GR-CP & 0.088 & 0.054 & 0.042 & 0.037 & \multirow{5}{*}{321} & \multirow{5}{*}{2058} \\
\hline & GR-AU & 0.106 & 0.065 & 0.052 & 0.045 & & \\
\hline & CP-AU & 0.018 & 0.011 & 0.009 & 0.008 & & \\
\hline & CP-TOA & 0.060 & 0.038 & 0.031 & 0.027 & & \\
\hline & AU-TOA & 0.042 & 0.027 & 0.022 & 0.019 & & \\
\hline \multirow{5}{*}{ Annual } & GR-CP & 0.094 & 0.060 & 0.049 & 0.043 & \multirow{5}{*}{1194} & \multirow{5}{*}{7420} \\
\hline & GR-AU & 0.116 & 0.075 & 0.061 & 0.054 & & \\
\hline & CP-AU & 0.022 & 0.015 & 0.013 & 0.011 & & \\
\hline & CP-TOA & 0.084 & 0.058 & 0.050 & 0.045 & & \\
\hline & AU-TOA & 0.062 & 0.043 & 0.037 & 0.033 & & \\
\hline
\end{tabular}




\section{Figures}

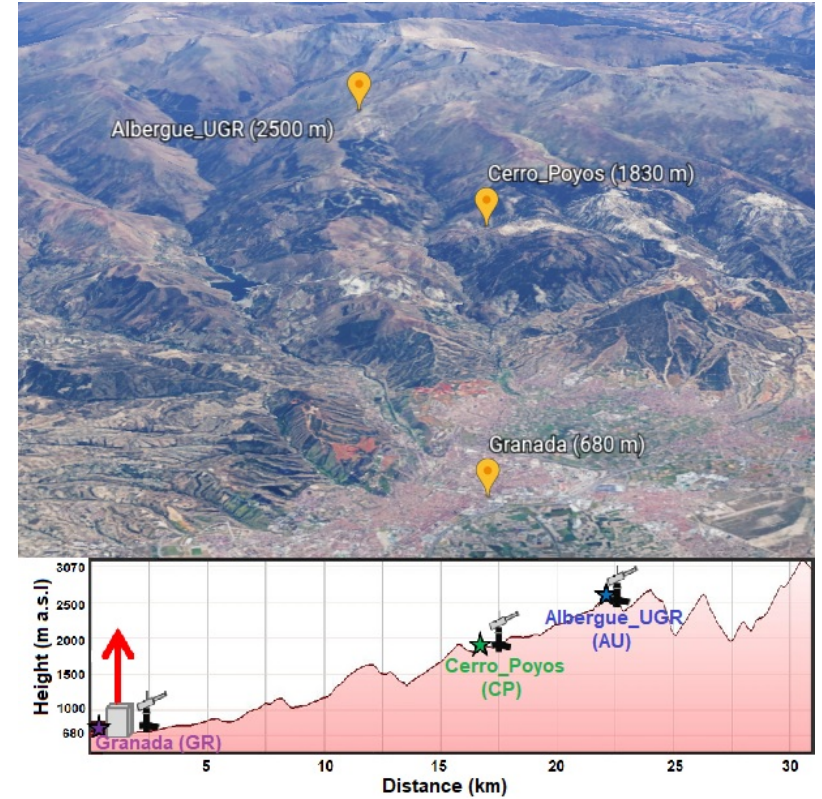

Figure 1: Map of part of Sierra-Nevada and surroundings where Granada, Cerro_Poyos and Albergue_UGR stations and their instrumentation are marked.
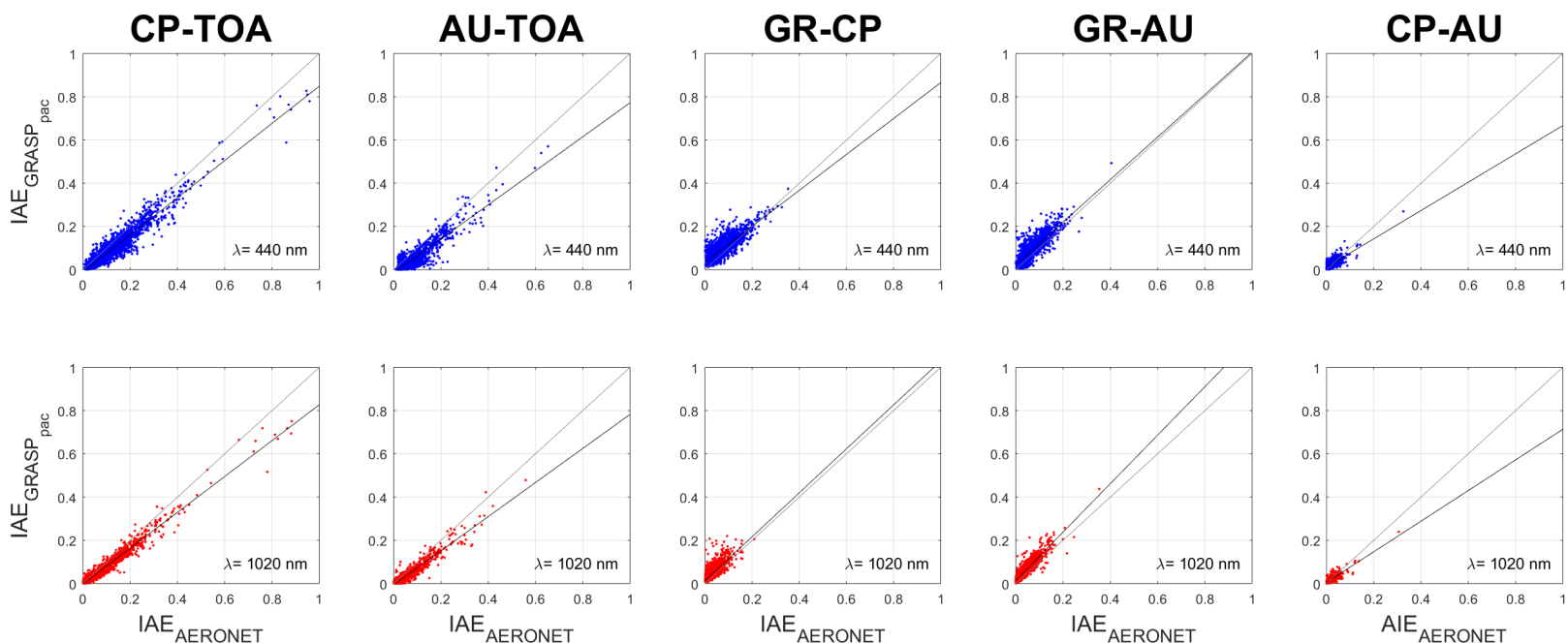

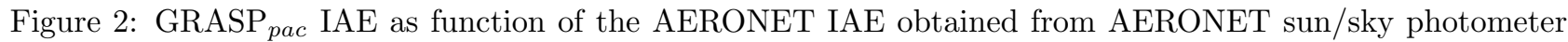
measurements in the same layers (CP-TOA, AU-TOA, GR-CP, GR-AU and CP-AU) at 440 nm (upper panels) and $1020 \mathrm{~nm}$ (bottom panels). The least square fit and the line 1:1 is also included. 

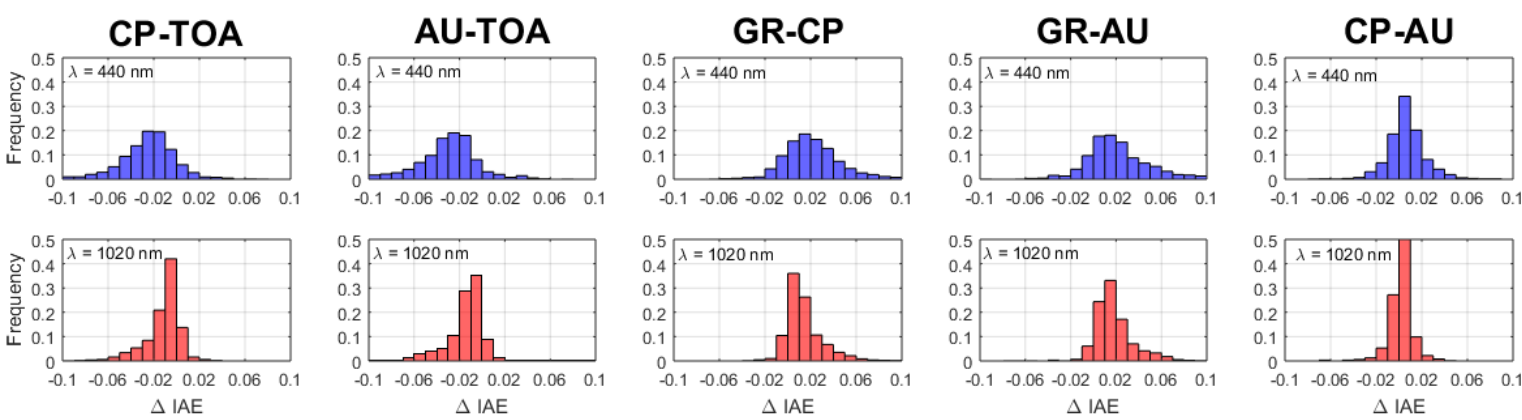

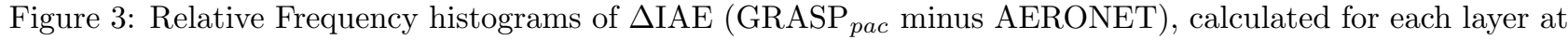
440 and $1020 \mathrm{~nm}$.

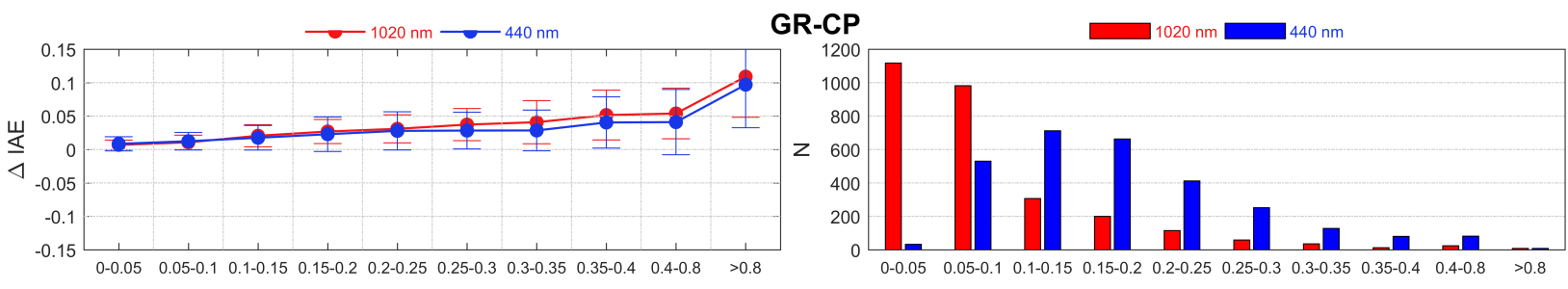

GR-AU
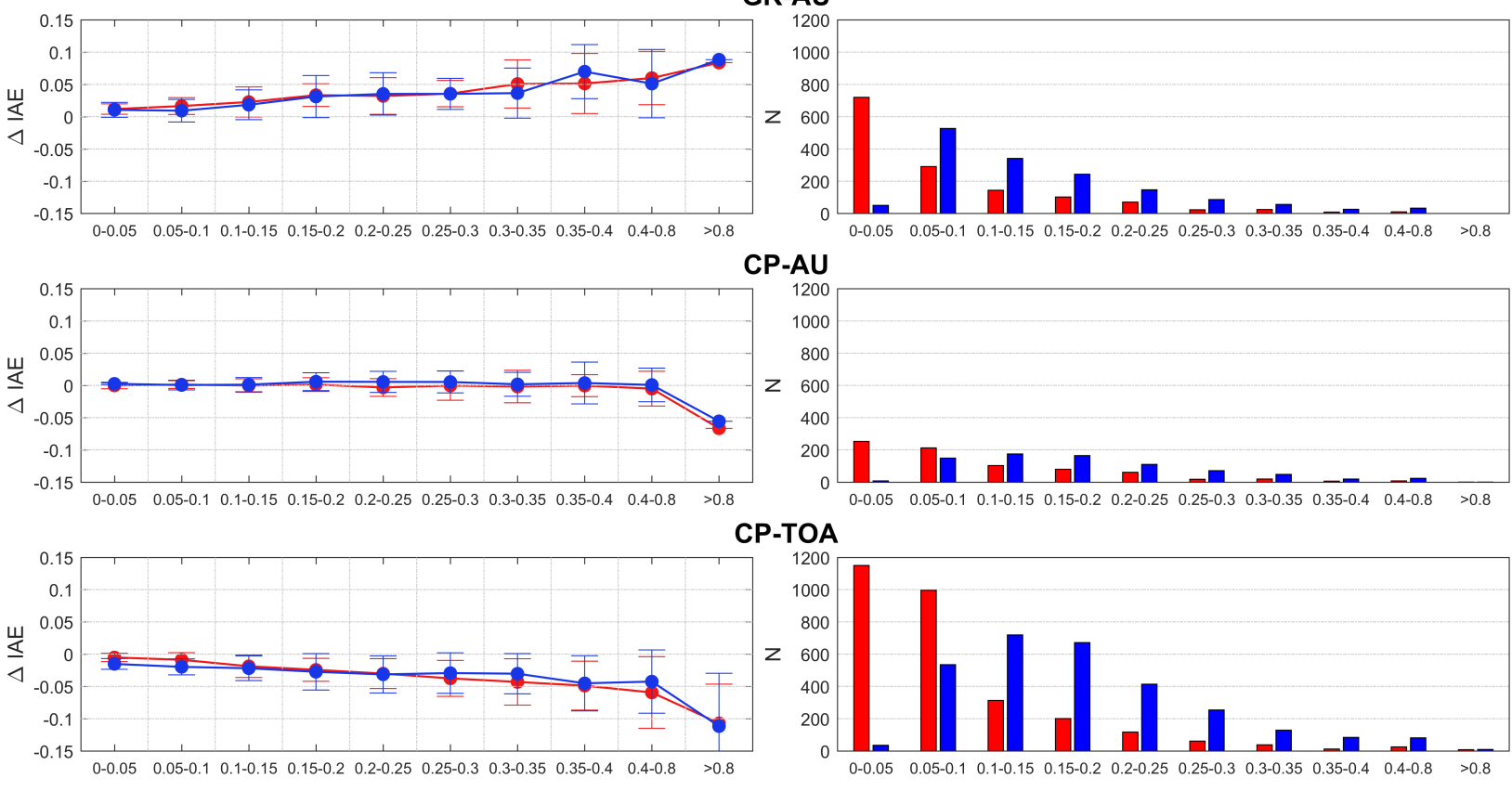

AU-TOA
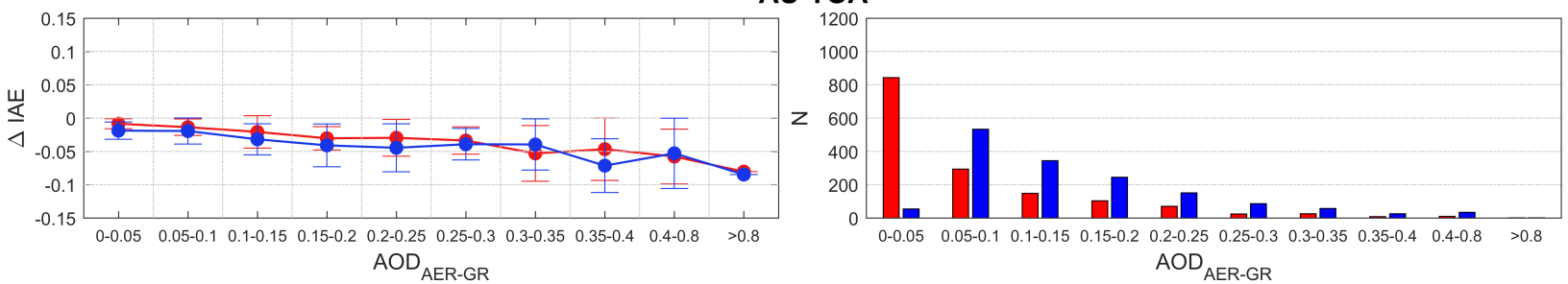

Figure 4: Mean (points) and standard deviation (error bars) of $\Delta$ IAE at 440 and $1020 \mathrm{~nm}$ and at different layers (CP-TOA, AU-TOA, GR-CP, GR-AU and CP-AU), for different bins of the AOD measured by Granada AERONET sun/sky photometer (AOD AER-GR) (left panels). The number of data (N) for each layer and wavelength is represented in the right panels. 


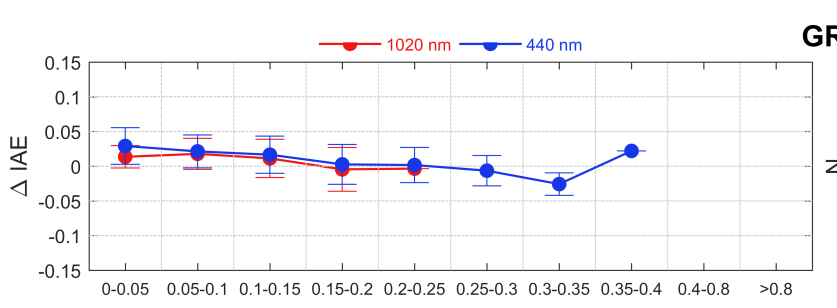

GR-CP

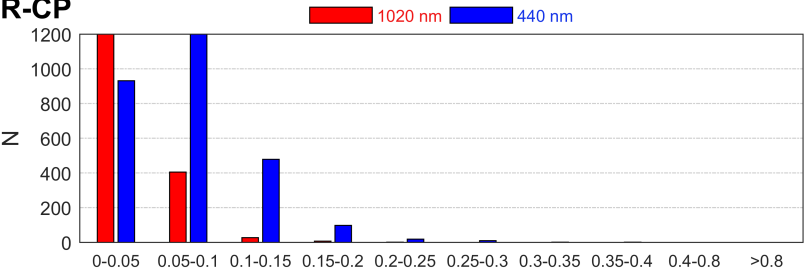

GR-AU
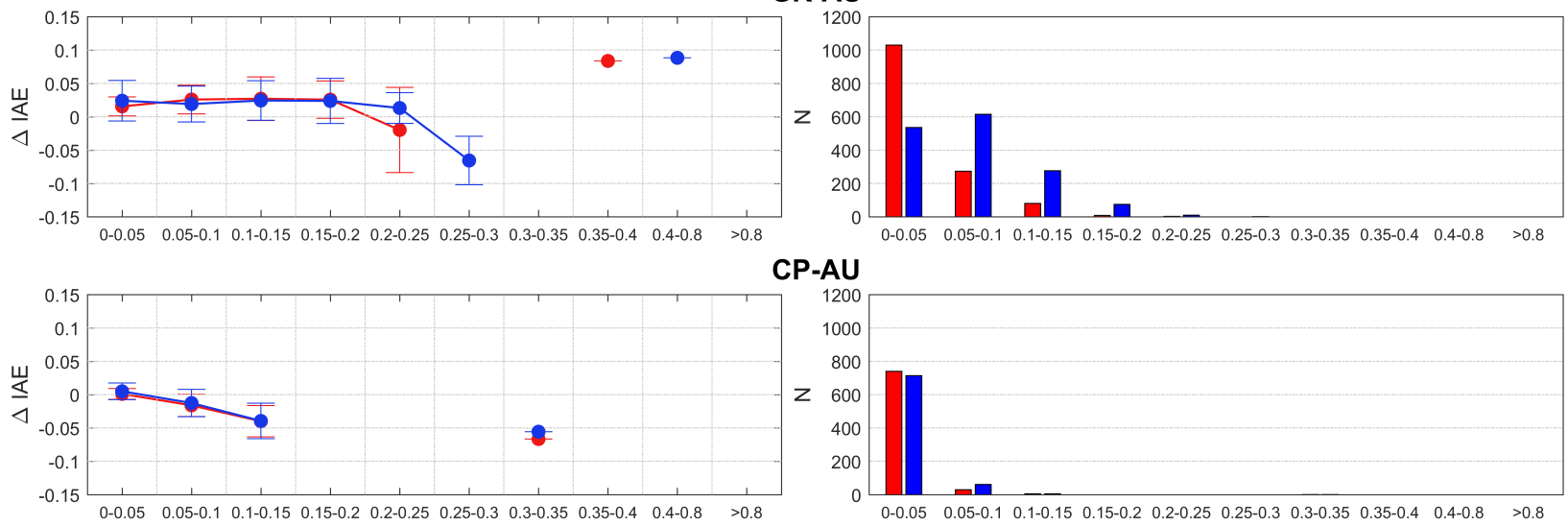

CP-TOA

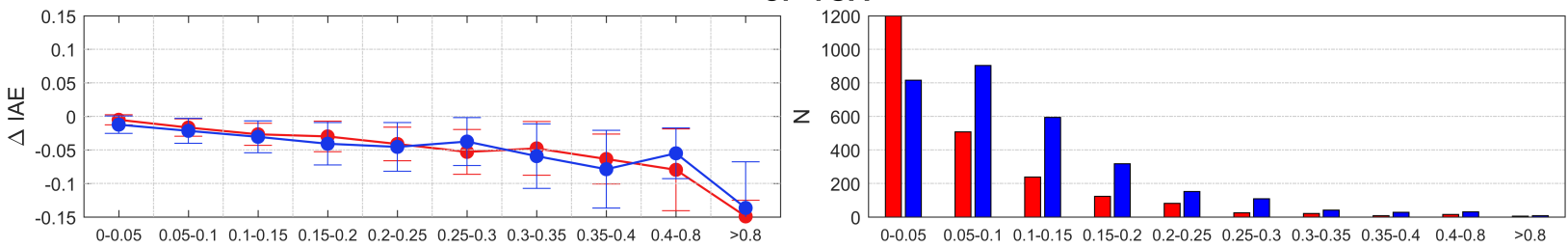

AU-TOA
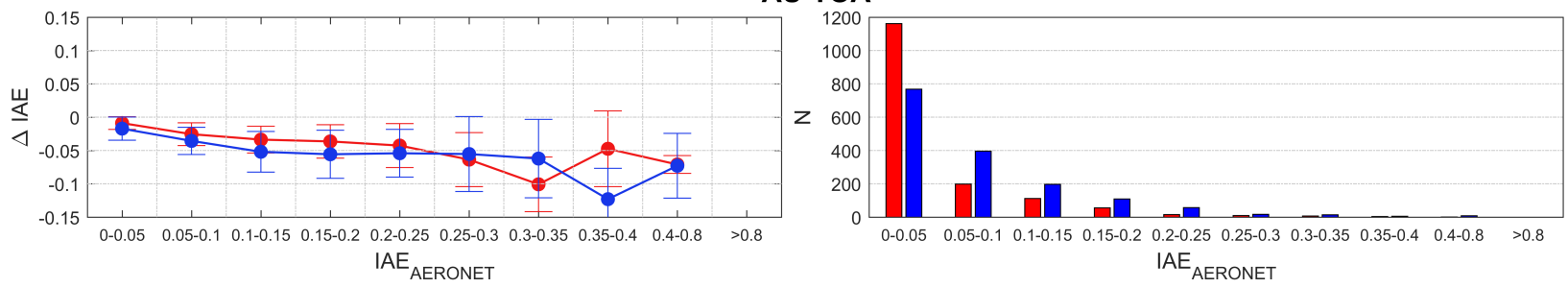

Figure 5: Mean (points) and standard deviation (error bars) of $\triangle \mathrm{IAE}$ at 440 and $1020 \mathrm{~nm}$ and at different layers (CP-TOA, AU-TOA, GR-CP, GR-AU and CP-AU), for different bins of the AERONET IAE of each layer (left panels). The number of data $(\mathrm{N})$ for each layer and wavelength is represented in the right panels. 

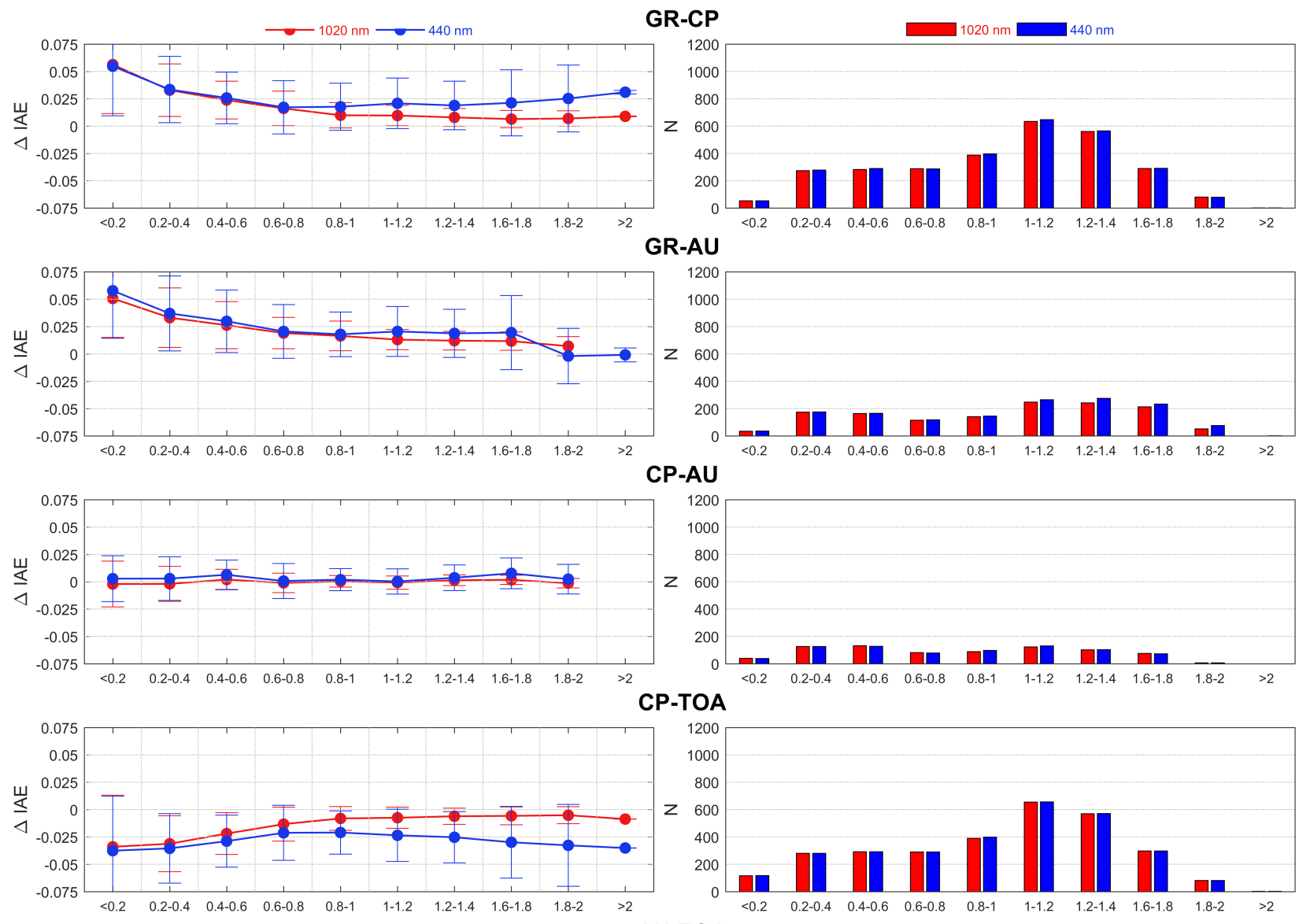

AU-TOA
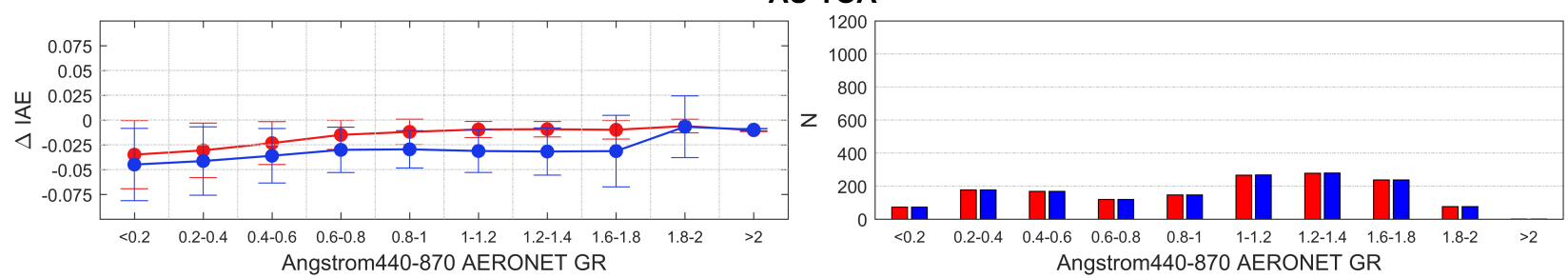

Figure 6: Mean (points) and standard deviation (error bars) of $\triangle \mathrm{IAE}$ at two wavelengths 440 and $1020 \mathrm{~nm}$, and at different layers (CP-TOA, AU-TOA, GR-CP, GR-AU and CP-AU), for different bins of the Ångström Exponent 440-870 nm derived by Granada AERONET sun/sky photometer (left panels). The number of data (N) for each layer and wavelength is represented in the right panels. 

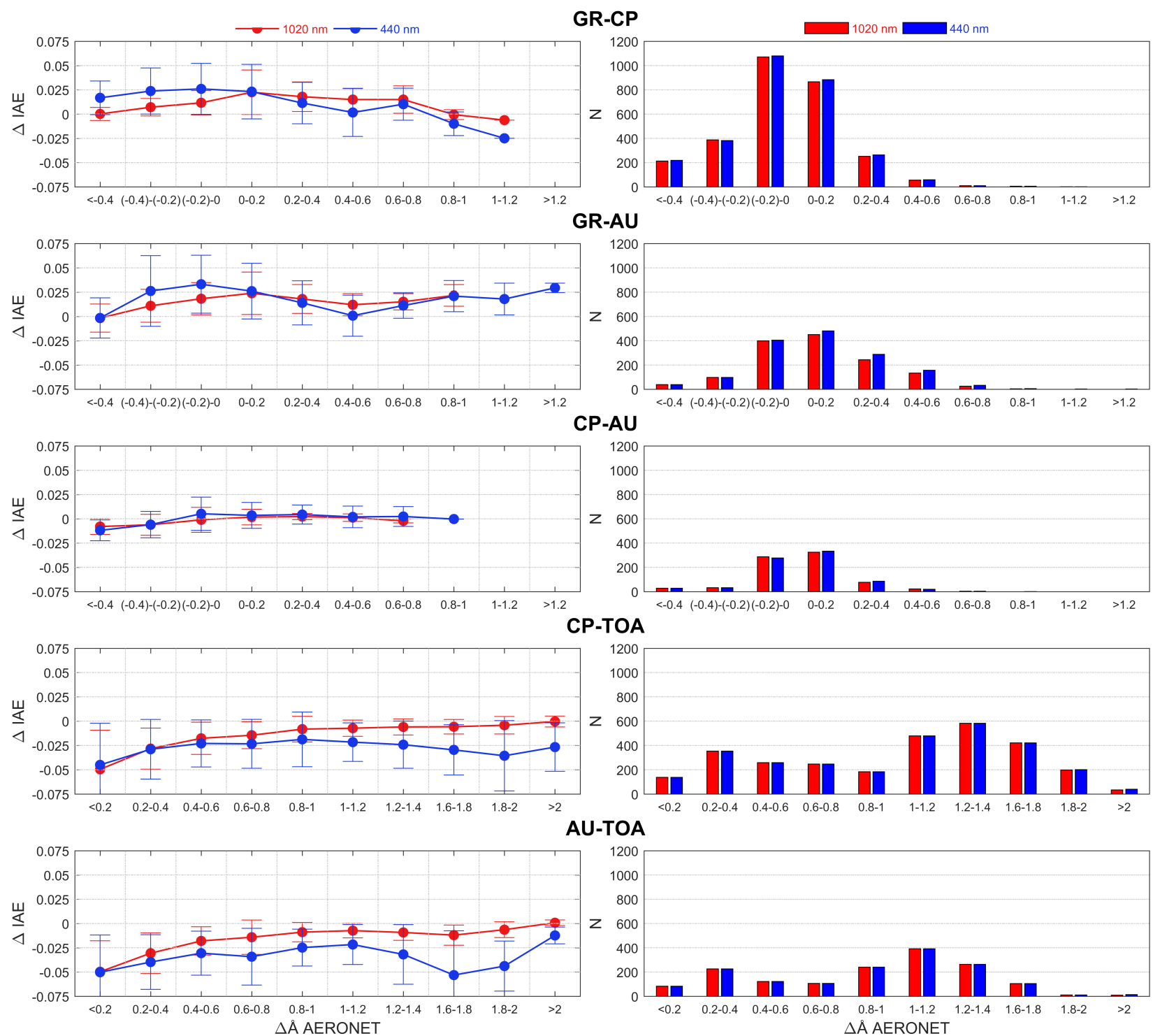

Figure 7: Mean (points) and standard deviation (error bars) of $\triangle \mathrm{IAE}$ at 440 and $1020 \mathrm{~nm}$, evaluated at different layers (CP-TOA, AU-TOA, GR-CP, GR-AU and CP-AU), for different bins of the Ångström exponent differences derived by the AERONET sun/sky photometers between the limits of each layer. The number of data $(\mathrm{N})$ for each layer and wavelength is represented in the right panels. 

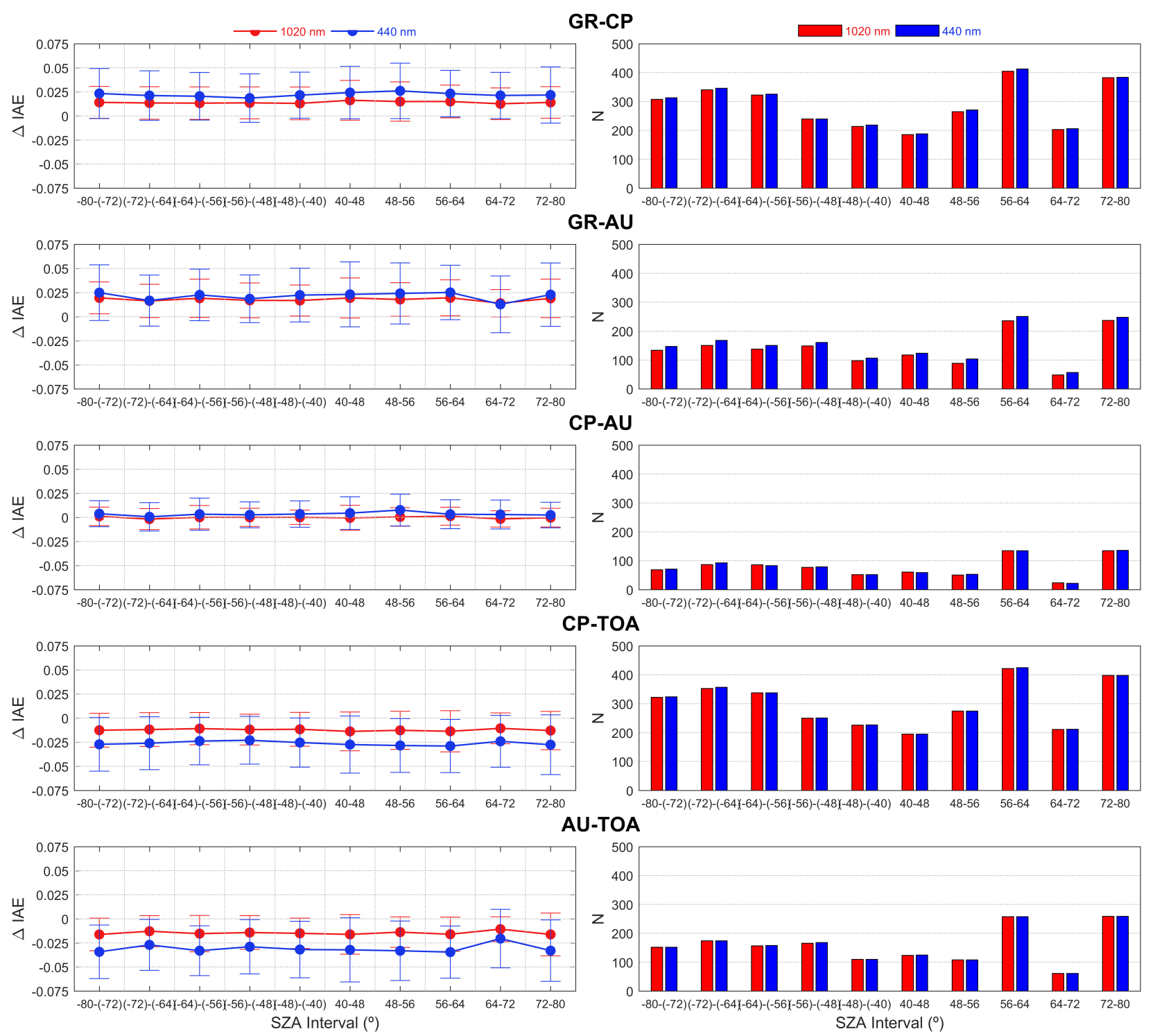

Figure 8: Mean (points) and standard deviation (error bars) of $\triangle \mathrm{IAE}$ at 440 and $1020 \mathrm{~nm}$, and at different layers (CP-TOA, AU-TOA, GR-CP, GR-AU and CP-AU), for different bins of the solar zenith angle when the measurements were made. The number of data $(\mathrm{N})$ for each layer and wavelength is represented in the right panels. 

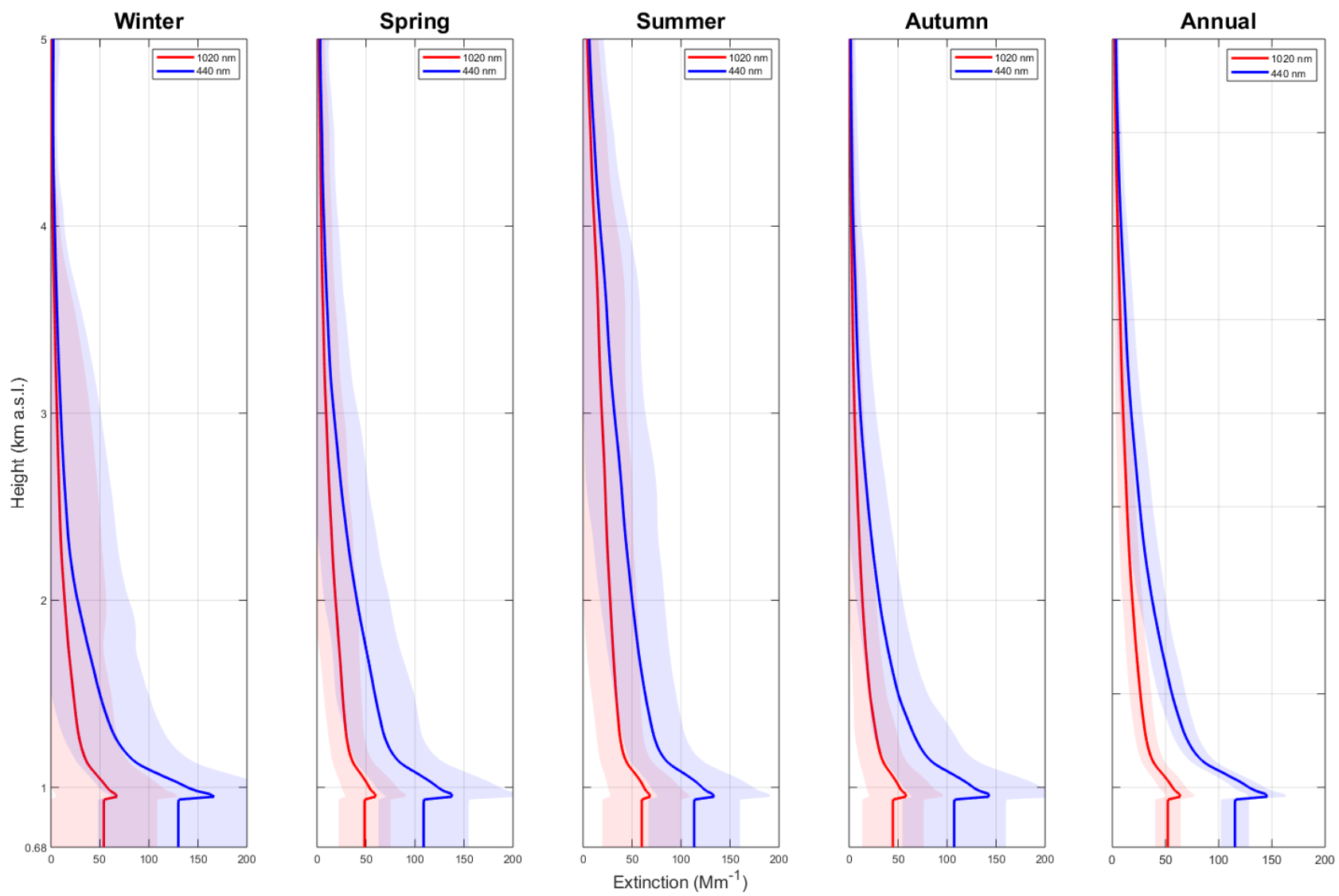

Figure 9: Seasonal and annual averages of the aerosol extinction vertical profiles at Granada obtained by GRASP $_{p a c}$ method at 440 and $1020 \mathrm{~nm}$ wavelengths. Shaded area corresponds to the standard deviation of each profile. 